\title{
Simulated Arctic atmospheric feedbacks associated with late summer sea ice anomalies
}

\author{
A. Rinke, ${ }^{1,2}$ K. Dethloff, ${ }^{2}$ W. Dorn, ${ }^{2}$ D. Handorf, ${ }^{2}$ and J. C. Moore ${ }^{1}$ \\ Received 1 February 2013; revised 16 June 2013; accepted 18 June 2013; published 26 July 2013.
}

[1] The coupled regional climate model HIRHAM-NAOSIM is used to investigate feedbacks between September sea ice anomalies in the Arctic and atmospheric conditions in autumn and the subsequent winter. A six-member ensemble of simulations spanning the period 1949-2008 is analyzed. The results show that negative Arctic sea ice anomalies are associated with increased heat and moisture fluxes, decreased static stability, increased lower tropospheric moisture, and modified baroclinicity, synoptic activity, and atmospheric large-scale circulation. The circulation changes in the following winter display meridionalized flow but are not fully characteristic of a negative Arctic Oscillation pattern, though they do support cold winter temperatures in northern Eurasia. Internally generated climate variability causes significant uncertainty in the simulated circulation changes due to sea ice-atmosphere interactions. The simulated atmospheric feedback patterns depend strongly on the position and strength of the regional sea ice anomalies and on the analyzed time period. The strongest atmospheric feedbacks are related to sea ice anomalies in the Beaufort Sea. This work suggests that there are complex feedback mechanisms that support a statistical link between reduced September sea ice and Arctic winter circulation. However, the feedbacks depend on regional and decadal variations in the coupled atmosphere-ocean-sea ice system.

Citation: Rinke, A., K. Dethloff, W. Dorn, D. Handorf, and J. C. Moore (2013), Simulated Arctic atmospheric feedbacks associated with late summer sea ice anomalies, J. Geophys. Res. Atmos., 118, 7698-7714, doi:10.1002/jgrd.50584.

\section{Introduction}

[2] Many observational studies indicate a link between Arctic summer sea ice decline and atmospheric circulation changes [e.g., Wu et al., 2006; Zhang et al., 2008; Simmonds and Keay, 2009; Overland and Wang, 2010] and discuss the causal connection with anomalously cold Eurasian winters [Honda et al., 2009; Francis et al., 2009; Petoukhov and Semenov, 2010; Liu et al., 2012; Cohen et al., 2012; Jaiser et al., 2012; Tang et al., 2013]. In this regard, the following feedback hypotheses are discussed: negative summer sea ice anomaly, increased heat and moisture fluxes, decreased vertical static stability and increased autumn lower tropospheric moisture, amplified baroclinic systems, changes in wintertime large-scale circulation, and cold winter temperatures in Eurasia.

[3] Actually, observations show no trend in winter Northern Hemisphere $(\mathrm{NH})$ land temperatures over the recent decades 1988-2010, but regionally, a significant cooling over North

\footnotetext{
${ }^{1}$ College of Global Change and Earth System Science, Beijing Normal University, Beijing, China.

${ }^{2}$ Alfred Wegener Institute Helmholtz Centre for Polar and Marine Research, Potsdam, Germany.

Corresponding author: J. C. Moore, College of Global Change and Earth System Science, Beijing Normal University, 19 Xinjiekou Wai St., Beijing 100875, China. (john.moore.bnu@gmail.com)

(C)2013. American Geophysical Union. All Rights Reserved. 2169-897X/13/10.1002/jgrd.50584
}

Europe and Eurasia is observed [Cohen et al., 2012]. Cohen et al. argue that a significant portion of this boreal winter cooling is driven by dynamic interaction with October Eurasian snow cover, which is linked to the summer sea ice retreat via the feedbacks discussed above. The ensemble of the global models of the Coupled Model Intercomparison Project Phase 5 cannot reproduce this observed cooling and simulates, on the contrary, a $\mathrm{NH}$ warming trend of $0.5^{\circ} \mathrm{C} / 10$ years in this recent period [Cohen et al., 2012].

[4] Most of the modeling studies which investigated the lagged atmospheric responses to recent Arctic summer sea ice changes apply atmosphere-only models [e.g., Honda et al., 2009; Strey et al., 2010; Kay et al., 2011; Blüthgen et al., 2012; Porter et al., 2012; Liu et al., 2012; Ghatak et al., 2012; Screen et al., 2013]. Atmosphere-only models are the ideal tool to isolate the impact of a surface forcing factor, such as a specifically given sea ice or sea surface temperature (SST) anomaly, on the atmospheric circulation. However, such studies lack potentially important ocean feedbacks. Studies with coupled atmosphere-ocean models with prescribed sea ice also exist [e.g., Orsolini et al., 2012]. Most of the studies are focused on the impact of the 2007 sea ice loss, although some used observed sea ice trends [e.g., Ghatak et al., 2012; Screen et al., 2013]. Some studies indicated that a high resolution and an Arctic-wide regional model would be advantageous in resolving feedbacks [Strey et al., 2010; Porter et al., 2012].

[5] In this paper, we analyze atmospheric feedbacks in autumn and winter to anomalously low September sea ice cover 


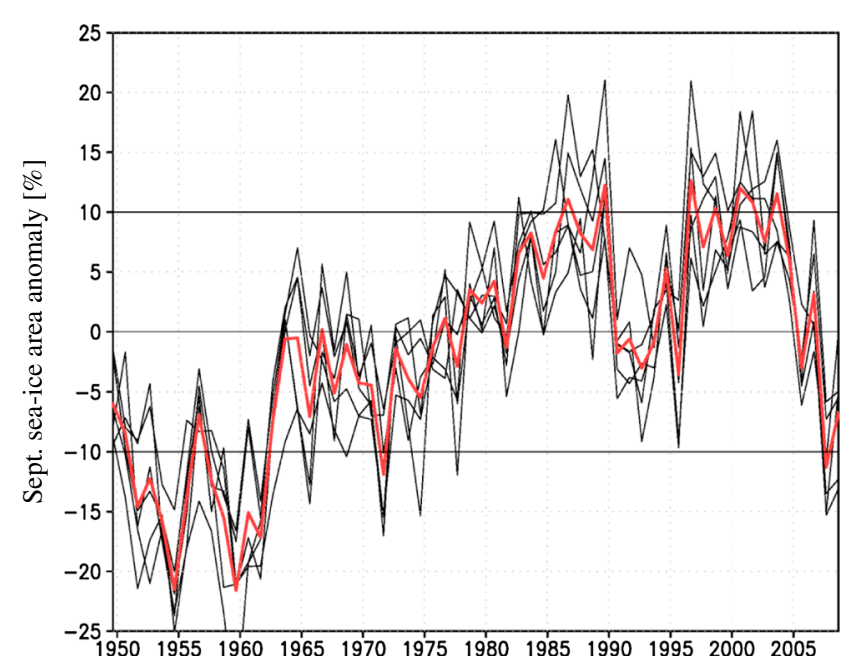

Figure 1. Simulated Arctic September sea ice area anomalies (\%; relative to 1961-1990), 1949-2008. The thick red line represents the ensemble mean, and the black lines represent the individual six ensemble members. Analyzed low- and high-ice years are those with anomalies larger than $-10 \%$ and $+10 \%$, respectively. The anomalies are always related to the average in the respective ensemble member.

by using an ensemble of simulations with the highresolution coupled atmosphere-ocean regional model HIRHAM-NAOSIM. In contrast with previous model studies, our approach uniquely analyzes coupled regional climate model (RCM) simulations which neither prescribe the (anomalous) sea ice nor are restricted to the 2007 case. Here we simulate the sea ice evolution during the 60 year period 1949-2008, using a fully coupled atmosphere-ocean-sea ice model. This study's strength, the use of a coupled model in which sea ice conditions may freely evolve, implies ambiguity in attributing the atmospheric responses solely to sea ice changes. For instance, it is difficult to separate the compounding influences of sea ice and SST anomalies in a coupled model.

[6] The applied Arctic RCM HIRHAM-NAOSIM takes advantage of realistic large-scale lateral forcing from reanalysis data and has an improved description of Arctic regional processes and feedbacks than a previous version of the model which together contribute to improved simulations [Dorn et al., 2009]. Thus, the model should be able to reproduce important sea ice-atmosphere relationships, particularly the cold-winter-temperature-related feedbacks. This is particularly relevant with respect to possible future model predictability studies on seasonal time scale, which likely require models to reproduce the relevant feedback chains and interactions [Orsolini et al., 2012].

[7] In section 2, we describe the model, the ensemble simulation setup, the selection of anomalous sea ice cases, and the analysis methods. Section 3 discusses the simulated atmospheric feedbacks to anomalous Arctic total sea ice area, such as the season mean responses and their uncertainty due to internal variability. Section 4 investigates the feedbacks to regional sea ice anomalies in different sectors of the Arctic Ocean. Section 5 extends the statistical evaluation of sea ice-atmosphere relations by comparing the simulations with observational data. Finally, section 6 summarizes the results and puts them into context with previous studies.

\section{Simulations and Analysis}

\subsection{Model and Simulations}

[8] The coupled Arctic RCM employed in this study is the HIRHAM-NAOSIM model which couples the atmospheric Arctic RCM HIRHAM [Dethloff et al., 1996] and the regional ocean-ice model covering the North Atlantic/Arctic Ocean (NAOSIM) [Karcher et al., 2003; Kauker et al., 2003]. A detailed and extensive description of the model was given by Rinke et al. [2003] and Dorn et al. [2007]. The simulations are performed over a circum-Arctic domain at a horizontal resolution of $50 \mathrm{~km}$ in the atmosphere (HIRHAM) and $25 \mathrm{~km}$ in the ocean (NAOSIM).

[9] Successful Arctic sea ice simulations have been presented with HIRHAM-NAOSIM by Dorn et al. [2009] and have shown that improved and harmonized parameterizations for sea ice growth and albedo, and snow cover on sea ice, lead to substantial improvements in the simulated summer sea ice. In a recent paper by Dorn et al. [2012], it has been shown that the simulated interannual variability in sea ice extent is in adequate agreement with observational data. The model ensemble simulations that we use in the present study were also extensively described in Dorn et al. [2012], and the reader is referred for all details of the ensemble setup there. Here only the most relevant features are described.

[10] The analyzed HIRHAM-NAOSIM ensemble consists of six hindcast simulations for the period 1949-2008, using National Centers for Environmental Prediction (NCEP)/ National Center for Atmospheric Research (NCAR) reanalysis data [Kalnay et al., 1996] as atmospheric boundary forcing. All ensemble members were started equally on 1 January 1948 and run through 31 December 2008, but the initial ocean and sea ice fields were taken from different years of a preceding coupled spin-up run of almost 11 years, which itself was initialized with ocean and sea ice fields of 25 February 1949 from a preexisting stand-alone NAOSIM simulation. The six individual ensemble runs were initialized with restart fields from six consecutive years, taken after 6 years of coupled spin-up simulation, when the sea ice and upper ocean are sufficiently adjusted. More concretely, the ocean and ice fields were initialized in ensemble run \#1 with the state of 1 January 1955 from the spin-up run. In ensemble run \#2, the ocean and ice fields were initialized with the state of 1 January 1956, etc., and in ensemble run \#6, the ocean and ice fields were initialized with the state of 1 January 1960. These six different Arctic Ocean initial states differ in the initial ice extent by up to $1 \times 10^{6} \mathrm{~km}^{2}$, i.e., relative difference of approximately $10 \%$, and in the initial ice volume by up to $20 \%$. We argue that the specific variations in the initial state should be a matter of no particular importance for our study.

\subsection{Composites of Low- and High-Sea-Ice Years}

[11] The September Arctic sea ice area and its anomaly, relative to 1961-1990, were calculated from the simulated sea ice concentration (SIC) for each year of the whole time series of 1949-2008 and for each of the six ensemble members. Using the calculated time series of the simulated September sea ice area anomaly (Figure 1), low- and highice years were selected for each ensemble member. These were averaged into composite means, and composite differences ("low minus high ice") were calculated. These six composite mean differences, one from each run, were then 

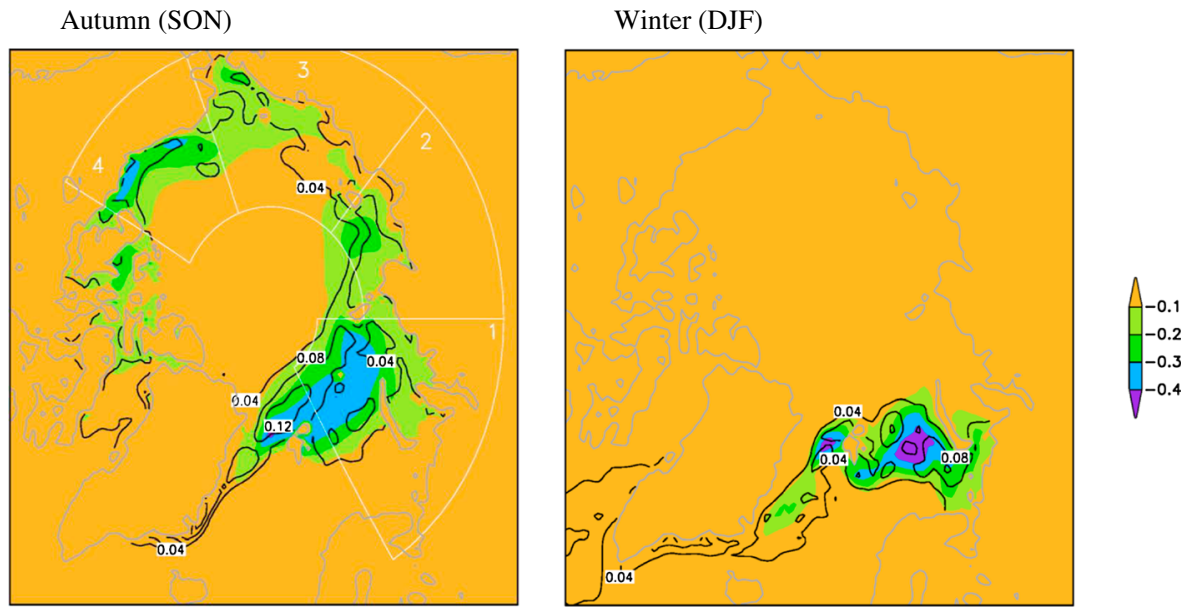

Figure 2. Simulated sea ice concentration difference "low minus high ice" for (left) autumn (SON) and (right) the following winter (DJF), averaged over the six ensemble members (shaded). The contours show the across-ensemble standard deviation of the difference. The left panel also highlights four different sectors of the Arctic Ocean (white lines) which were used to calculate regional sea ice anomalies (see section 4).

(a) srfc. temp. and heat fluxes

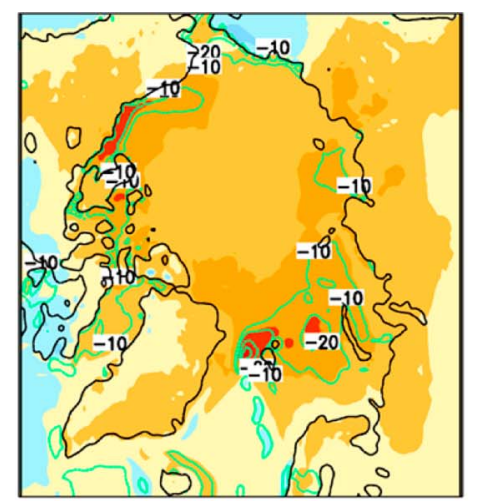

(c) geopot.diff. z500-z850

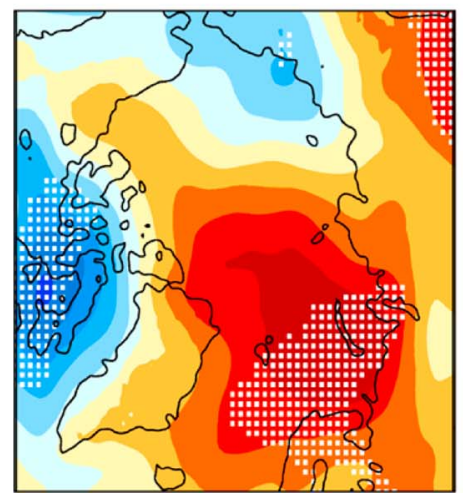

(b) temp.diff. t850-tsrfc

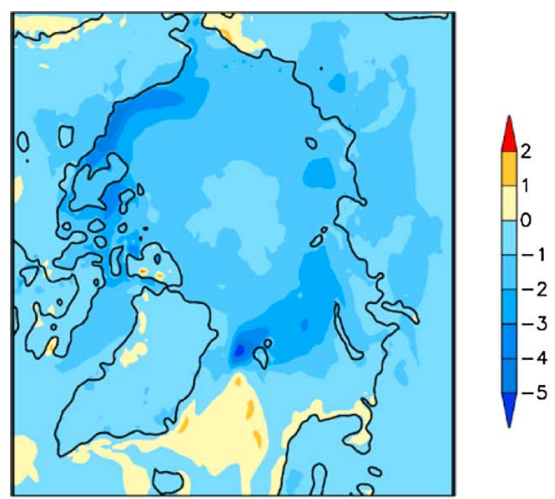

(d) vert.int. moisture

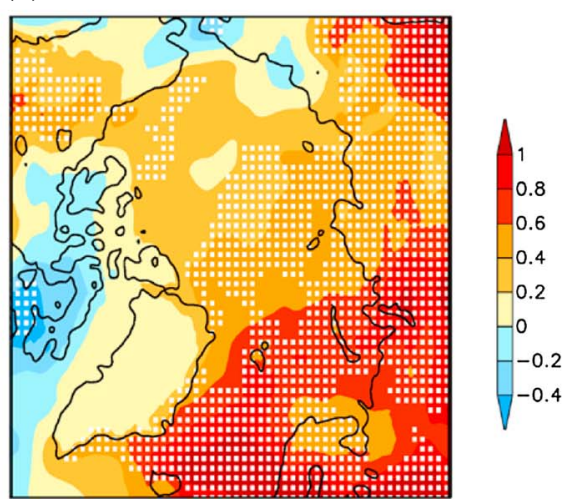

Figure 3. Simulated atmosphere differences "low minus high ice" for autumn (SON), averaged over the six ensemble members. (a) Surface temperature (K; shaded) and total of sensible and latent heat fluxes (W/ $/ \mathrm{m}^{2}$; negative: upward; green contour), (b) lower atmospheric temperature difference (K; t850-tsrfc), (c) geopotential thickness difference (m; z500-z850), (d) vertically integrated specific humidity $\left(\mathrm{kg} / \mathrm{m}^{2}\right)$, (e) mean sea level pressure (hPa; SLP), (f) $500 \mathrm{hPa}$ geopotential height (m; z500), (g) standard deviation of 2-6 day filtered SLP (hPa; shaded; low-ice conditions are displayed by green contours), and (h) Eady growth rate (1/d). The white dots delimit the $95 \%$ significance level of the shaded differences. 
(e) SLP

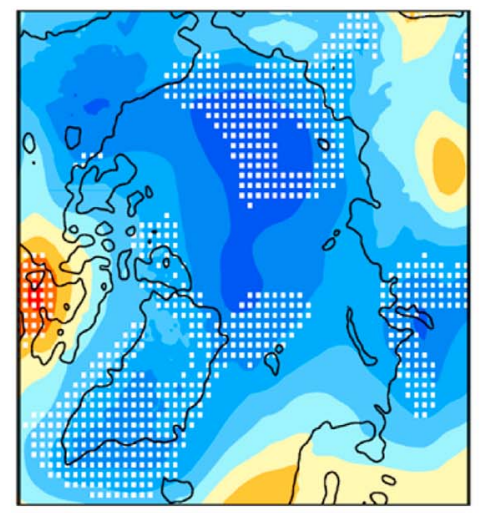

(g) SLP stdev

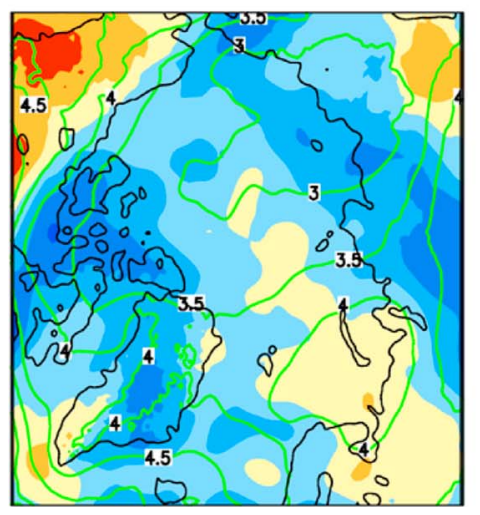

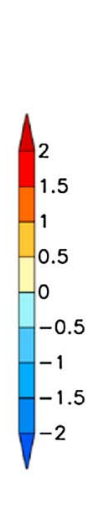

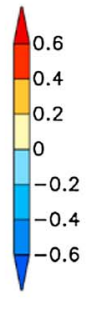

(f) $\mathrm{z} 500$

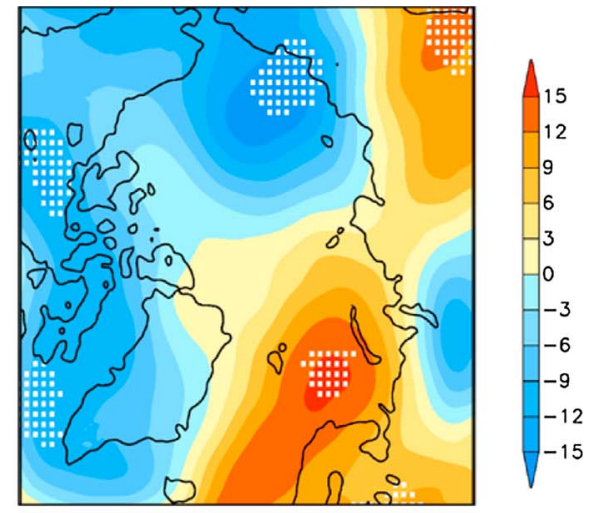

(h) Eady growth rate

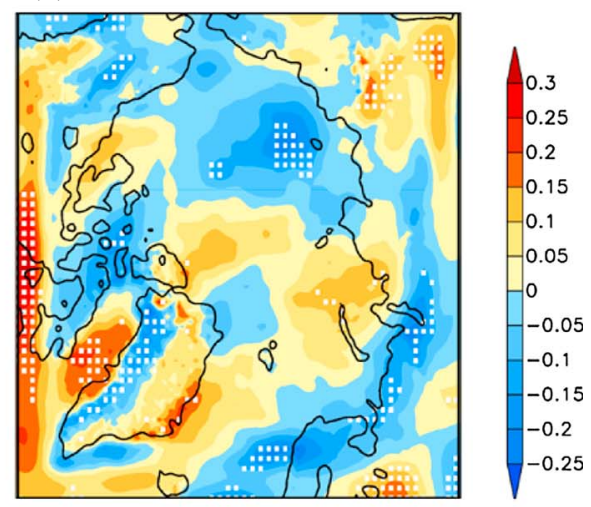

Figure 3. (continued)

averaged. Low- and high-ice cases were selected when the ice area anomaly was larger than $-10 \%$ and $+10 \%$, respectively. This $10 \%$ threshold is approximately equivalent to a one-standard-deviation anomaly. The anomalies are always related to the average in the respective ensemble member. The number of anomalously low or high ice years ranges, on this basis, between 5 and 14 among the six ensemble members. All in all, the composite analysis uses 69 cases for low-ice conditions and 39 cases for high-ice conditions.

[12] Figure 2 shows the simulated autumn and following winter SIC differences between the composites of low- and high-ice cases. The largest sea ice reductions (up to -40\%) occur during autumn in the northern Barents, Kara, Laptev, East Siberian, Chukchi, and Beaufort Seas, and also in the Fram Strait. In the following winter, the sea ice reductions occur over the entire Barents Sea and the eastern Greenland Sea. The small magnitude of the across-ensemble standard deviation (0.02-0.08 in most areas) indicates the general agreement of those sea ice changes among the individual members. For the most part, the maxima of SIC anomaly and of its variance are co-located. This indicates that it is only the strength of the anomalies that varies among the individual ensemble members, but not their location, which is always restricted to the more vulnerable marginal ice edge zone where the transition from dense pack ice to open water occurs. To investigate the feedbacks to regional sea ice anomalies, composites of low- and high-sea-ice years were calculated for four different sectors of the Arctic Ocean (see section 4).

\subsection{Analysis}

\subsubsection{Composite Differences}

[13] To examine atmospheric signals that may be caused by sea ice anomalies, composites of atmospheric variables for the selected low- and high-ice cases were calculated for each of the six ensemble members (see section 2.2). Seasonal differences "low minus high ice" for autumn (September-November (SON)) and the following winter (December-February (DJF)) are discussed. In addition to temperature, moisture, and pressure fields, changes in synoptic activity were calculated. The temporal standard deviation of daily (0 UTC) sea level pressure (SLP) fields, filtered for 2-6 days, was used as an indicator of synoptic activity. Further, we calculated the Eady growth rate $(\sigma)$ which assesses baroclinic instability through the vertical gradient in horizontal wind speed in the troposphere and a measure of static stability [Hoskins and Valdes, 1990], as $\sigma=0.31 \times(\mathrm{f} / \mathrm{N}) \times|\delta(\mathrm{u}, \mathrm{v}) / \delta \mathrm{z}|$, where $\mathrm{f}$ is the Coriolis parameter, $\mathrm{N}$ is the Brunt-Väisälä frequency, $\delta(\mathrm{u}, \mathrm{v}) / \delta \mathrm{z}$ is the vertical wind shear, $\mathrm{u}$ and $\mathrm{v}$ are the horizontal wind fields, and $\mathrm{z}$ is the geopotential height $(500 \mathrm{hPa}$ and $850 \mathrm{hPa}$ were used as the upper and lower pressure levels). The calculated Eady growth rate is based on monthly data, and we interpret changes in the Eady growth rate as changes in the baroclinic fraction of long planetary waves.

\subsubsection{Statistical Significance and Uncertainty}

[14] The statistical significance of the calculated atmospheric differences was estimated using Student's $t$ test with 95\% 
(a) srfc. temp. and heat fluxes

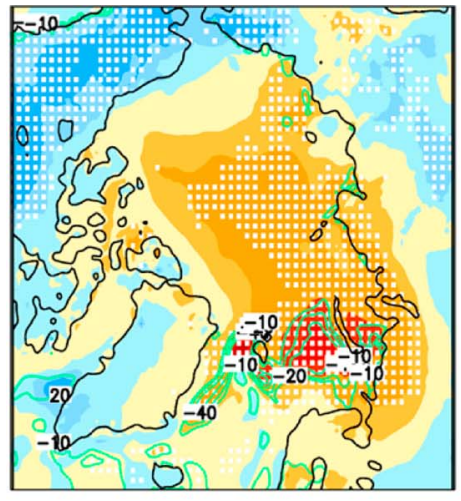

(c) geopot.diff. z500-z850

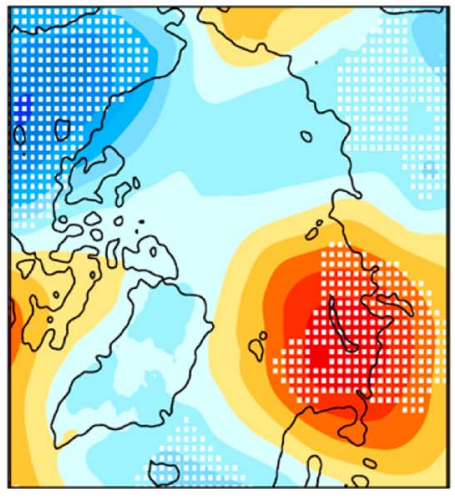

(e) SLP

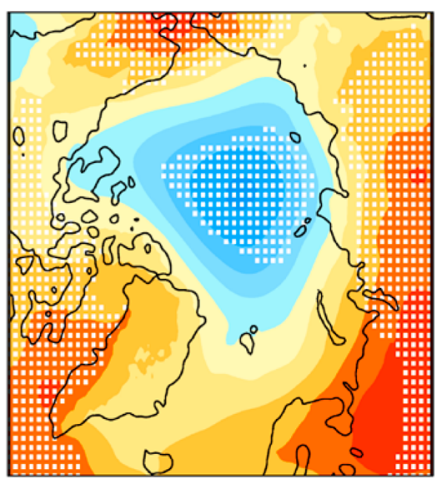

(g) SLP stdev

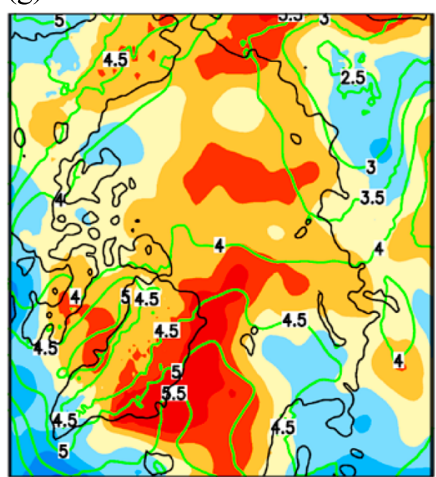

(b) temp.diff. t850-tsrfc

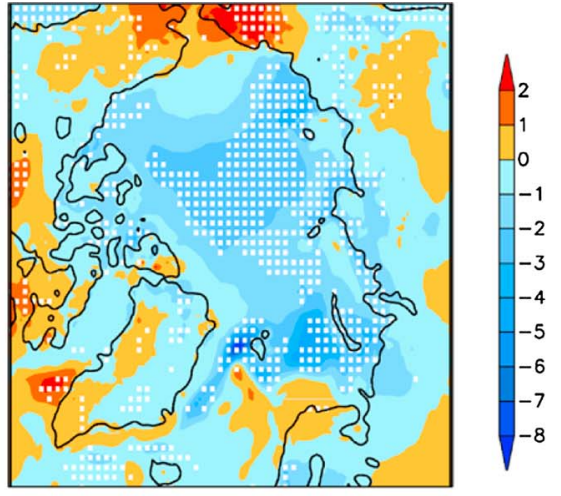

(d) vert.int. moisture

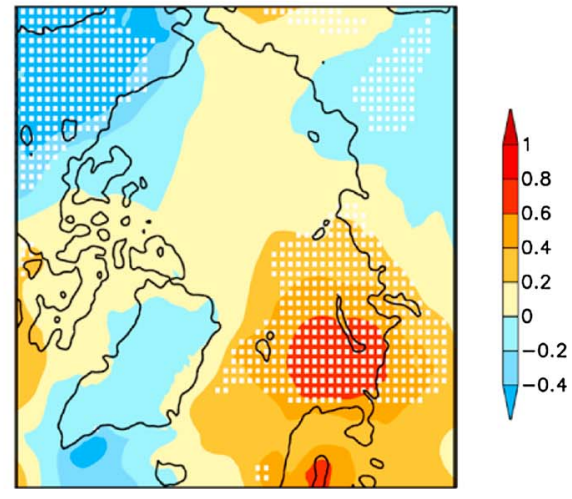

(f) z500

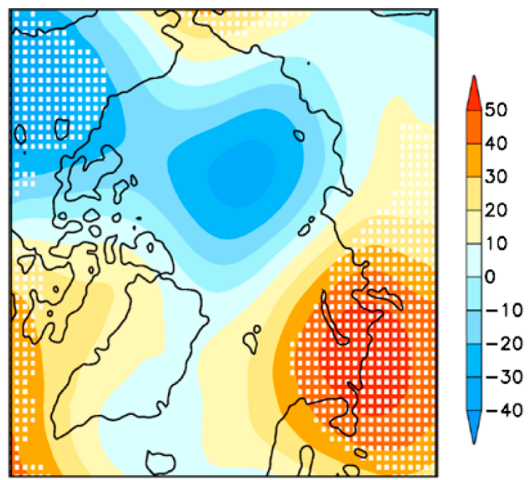

(h) Eady growth rate

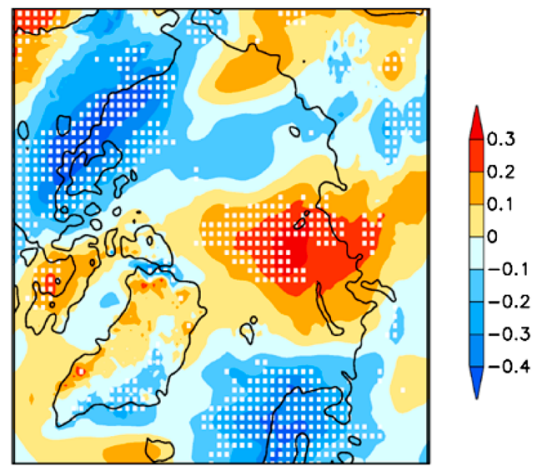

Figure 4. As in Figure 3 but for winter (DJF). 
(a) srfc. temperature

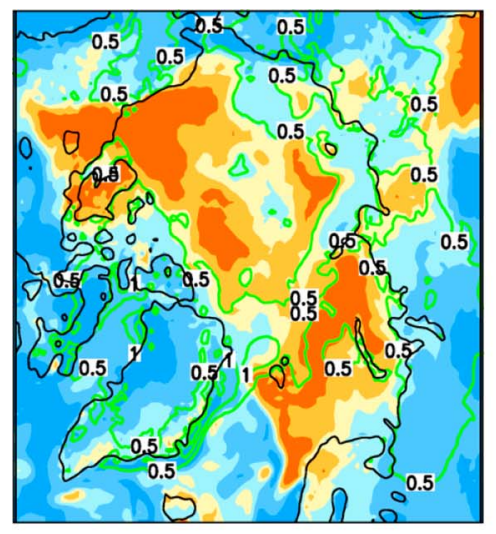

(c) SLP

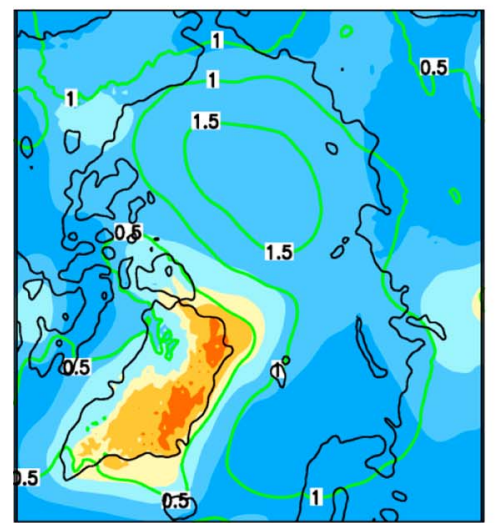

(b) vert. int. moisture

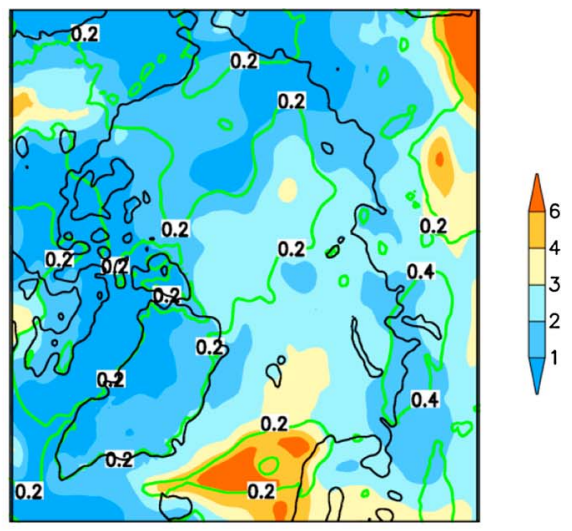

(d) $\mathrm{z} 500$

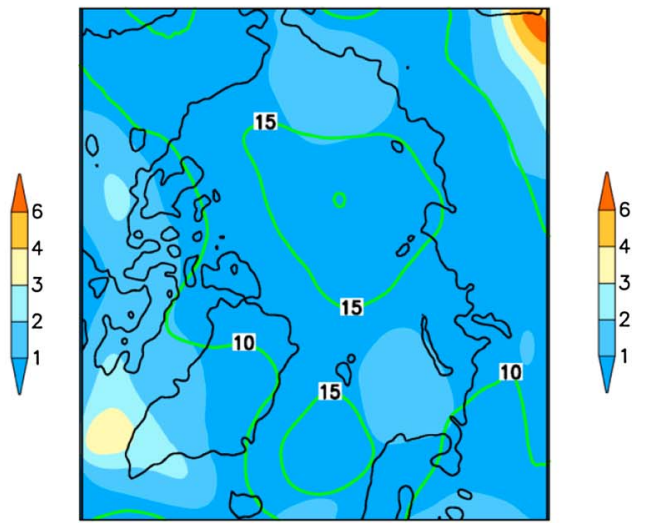

Figure 5. Across-ensemble standard deviation (contours; given units) and absolute value of the ratio between ensemble mean and across-ensemble standard deviation (shaded; dimensionless) of the simulated differences "low minus high ice" for autumn (SON). (a) Surface temperature $\left({ }^{\circ} \mathrm{C}\right),($ b) vertically integrated specific humidity $\left(\mathrm{kg} / \mathrm{m}^{2}\right)$, (c) mean sea level pressure (hPa; SLP), and (d) $500 \mathrm{hPa}$ geopotential height (m; z500).

confidence level. To assess the robustness of the ensemble mean differences "low minus high ice," the across-ensemble scatter of these differences was determined by the across-ensemble standard deviation (SD), calculated across the six-ensemblemember differences "low minus high ice." A small value of $\mathrm{SD}$, along with a large ratio between the absolute value of the ensemble mean difference and SD (called "signal-to-noise ratio" (SNR)), indicates strong agreement among the six individual ensemble members and a robust response.

\subsubsection{Further Statistical Analyses}

[15] A maximum covariance analysis (MCA) [von Storch and Zwiers, 1999; Jaiser et al., 2012] was conducted to describe the relation between September SIC and SLP in the following autumn and winter. By means of MCA, an orthonormal set of patterns is determined by maximizing the covariance between the related expansion coefficients. The related eigenvalue problem can be solved by singular value decomposition of the cross-covariance matrix between the two fields. The MCA was performed for the simulated fields for the whole period 1949-2008 and also for the last 30 years 1979-2008 to facilitate comparison with observational data. For the latter, SLP from the ERA-Interim reanalysis data [Dee et al., 2011] on a $2^{\circ} \times 2^{\circ}$ latitude/longitude grid and SIC from the Hadley Centre's sea ice data set (HadISST1) [Rayner et al., 2003] on a $1^{\circ} \times 1^{\circ}$ latitude/longitude grid were used. The results of this analysis (section 5) are pairs of patterns for SIC and SLP that are expected to occur simultaneously, coupled through the maximized covariance of their associated time series. The signs of the presented patterns are arbitrary; the values of the anomalies at a given time are determined by the product of related expansion coefficients with the anomaly patterns.

\section{Atmospheric Feedbacks to Anomalous September Arctic Sea Ice Area}

\subsection{Composite Differences "Low Minus High Ice"}

\subsubsection{Autumn}

[16] The major direct impact of sea ice anomalies on the atmosphere is through changed surface sensible and latent heat fluxes. Accordingly, stronger upward heat fluxes occur over the locations with reduced sea ice during low-ice years (Figure 3a). Enhanced upward heat fluxes occur particularly in the Kara, Chukchi, and Beaufort Seas with changes of up to $40 \mathrm{~W} / \mathrm{m}^{2}$. The associated increase of surface air temperature, distinctively captured over the regions of sea ice anomaly, is significant, and up to $6 \mathrm{~K}$ (Figure $3 \mathrm{a}$ ). The temperature response extends to higher pressure levels but is strongest near the surface, which results in weakened static stability and is expressed in a decreased temperature gradient between 
(a) srfc. temperature

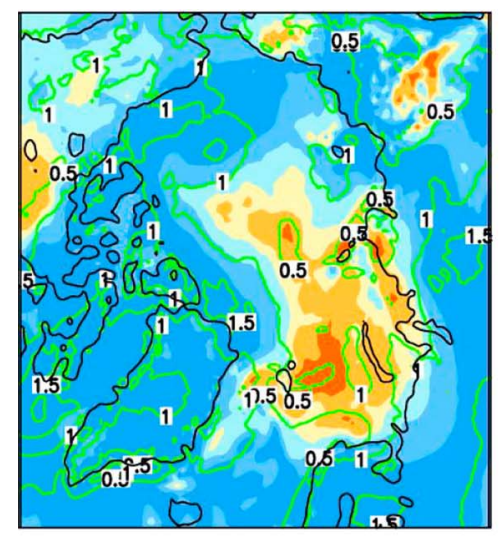

(c) SLP

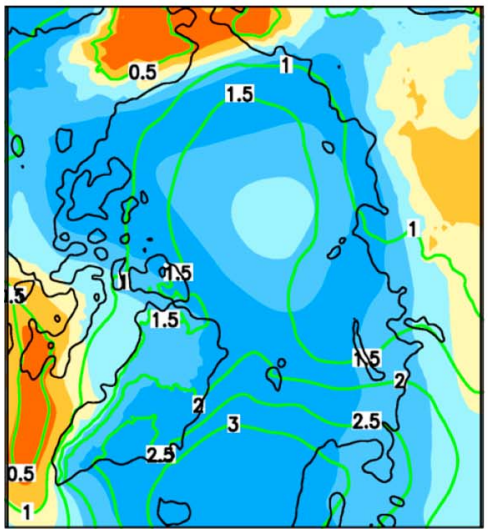

(b) vert. int. moisture

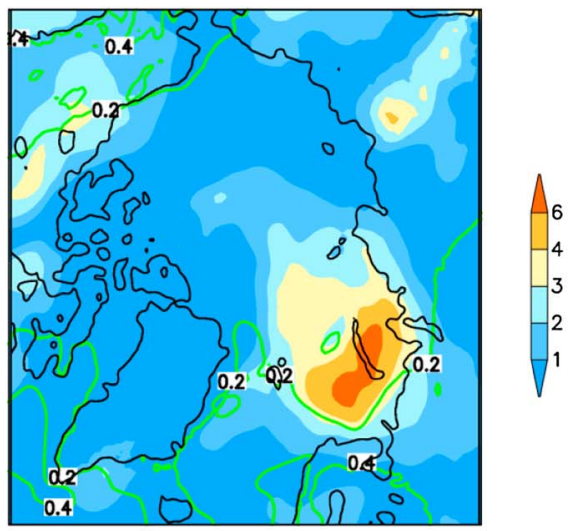

(d) z500

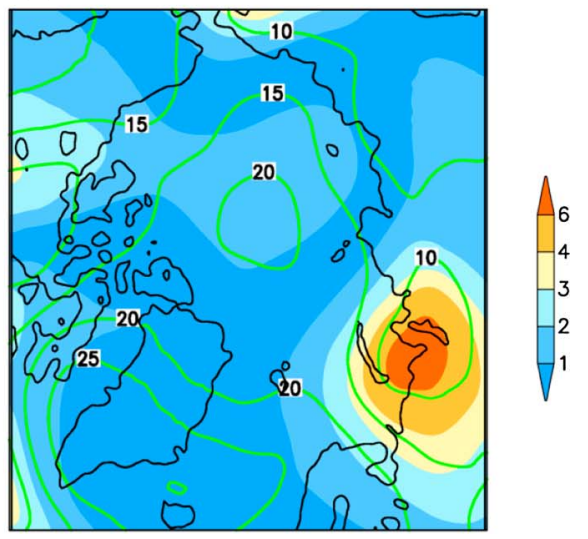

Figure 6. As in Figure 5 but for winter (DJF).

$850 \mathrm{hPa}$ and the surface (Figure 3b). Further, Figure 3c shows that the whole lower troposphere is warmed extensively, indicated by an increased 500-850 hPa geopotential thickness of up to $15 \mathrm{~m}$, centered over the Barents and Kara Seas, and with a band of greater thickness extending from the East Siberian Sea to northern Alaska/Canada. These thermal responses are accompanied by the moistening of the atmospheric column by $0.2-0.8 \mathrm{~kg} / \mathrm{m}^{2}$ in most parts of the Arctic (Figure 3d). The temperature and moisture signals are opposite over Far East Siberia and Northeastern North America, where surface and tropospheric cooling and drying occur.

[17] One could expect that the warmer and moister atmosphere could lead to increased cloud cover, but the simulated changes in total cloud cover are not statistically significant. Previous studies arrive at inconsistent results concerning this matter. While Kay and Gettelman [2009] show that increased turbulent heat and moisture transport promotes low-cloud formation, Schweiger et al. [2008] report that low-level clouds may decrease and midlevel clouds may simultaneously increase. They argue that a decreased static stability and an atmospheric boundary layer (ABL) deepening contribute to a rise in cloud level. Simulations by Porter et al. [2012] support the finding of Schweiger et al. [2008] through to the middle of September but show more low-level clouds from October to November in accordance with the results of Kay and Gettelman [2009]. The model study of Screen et al. [2013] shows that low-level cloud cover responses are statistically insignificant and are highly sensitive to the model chosen.

[18] The large-scale atmospheric dynamical response is of strong baroclinic nature, associated with different patterns of pressure anomalies at the surface and in the midtroposphere (Figures $3 \mathrm{e}$ and $3 \mathrm{f}$ ). The SLP change is characterized by a slight (and partly significant) decrease over the central Arctic (by up to $-2.5 \mathrm{hPa}$ ) and a slight increase over lower latitudes of North Atlantic/North Europe, Siberia, and Northeast Canada. The corresponding positive/negative responses in $500 \mathrm{hPa}$ geopotential height (z500) are located over the Barents, Kara/East Siberian, and Chukchi Seas and are up to $\pm 15 \mathrm{~m}$.

[19] In low-ice years, synoptic activity is particularly strengthened over the Barents Sea, the Labrador Sea/Baffin Bay, southern Siberia, and Alaska and reduced over the Canadian Archipelago (Figure 3g). Generally, the changes in synoptic activity are accompanied by modifications of the same sign in the baroclinicity (change in Eady growth rate; Figure $3 \mathrm{~h}$ ), seen, e.g., over the Barents/Kara Seas, Laptev/East Siberian Seas, and Labrador Sea. These are regions where cyclones pass. In accordance with Teng et al. [2008], the changes in synoptic activity are related to changes in the upstream baroclinicity. However, regions with opposing responses are obvious; e.g., the reduced synoptic activity over the Canadian Archipelago is partly compensated by an 
$\underline{\text { Region } 1 \text { (Barents/Kara Seas) }}$
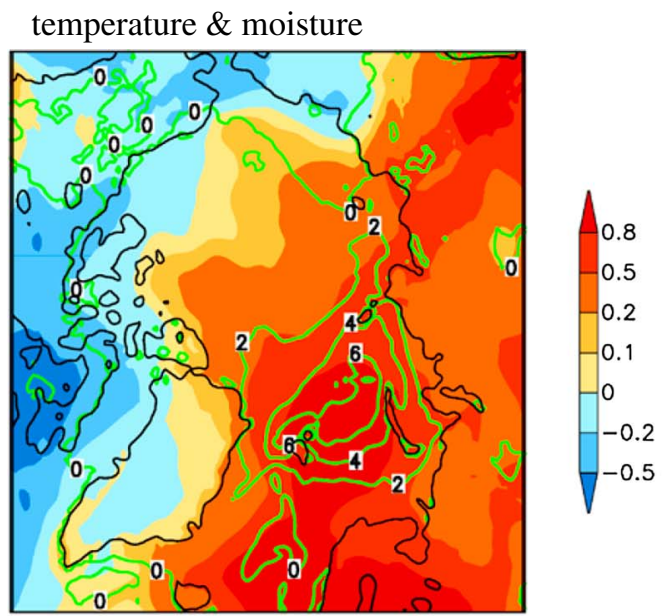

Region 2 (Laptev Sea) temperature \& moisture

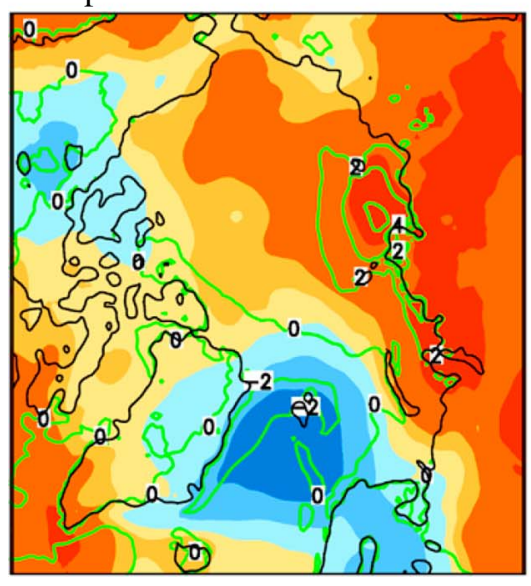

z500 \& SLP

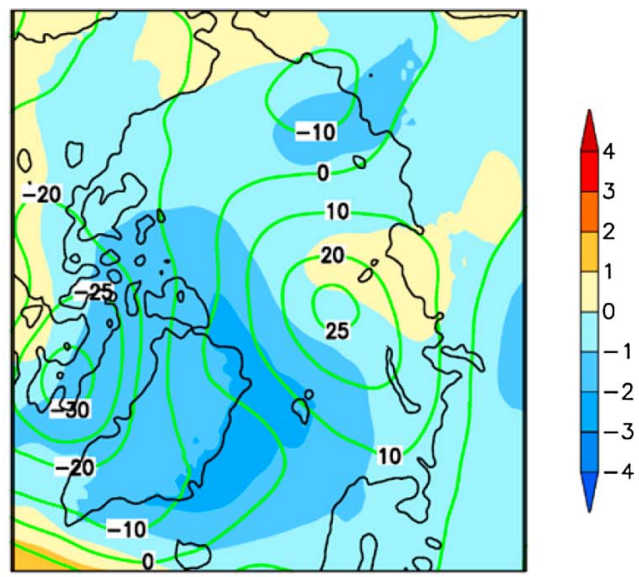

z500 \& SLP

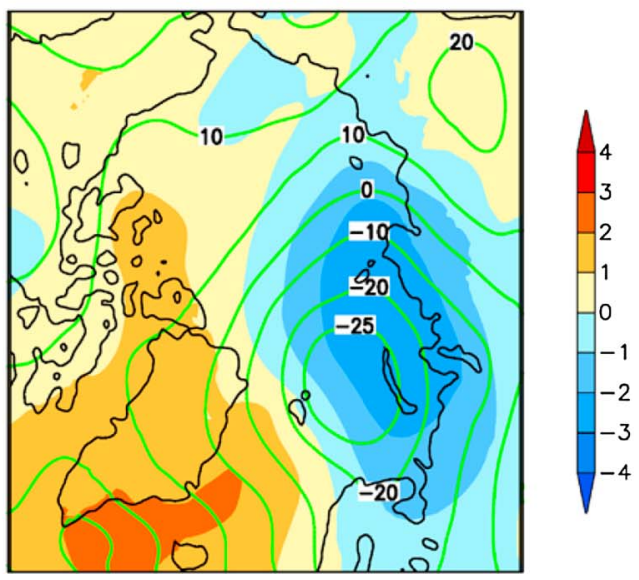

Figure 7. Simulated atmosphere differences "low minus high ice" for the four different regions for autumn (SON), averaged over the six ensemble members. (left) Surface temperature $\left({ }^{\circ} \mathrm{C}\right.$; contours) and vertically integrated specific humidity ( $\mathrm{kg} / \mathrm{m}^{2}$; shaded); (right) $500 \mathrm{hPa}$ geopotential height (m; z500; contours) and mean sea level pressure (hPa; SLP; shaded).

increased baroclinic fraction of long planetary waves. Such a compensating effect also appears over Scandinavia and the Western Russian Arctic.

\subsubsection{Following Winter}

[20] Again, the changes in heat fluxes and near-surface temperature show well-defined maxima around the locations of sea ice changes. Due to the large wintertime oceanatmosphere temperature difference, the changed sensible and latent heat fluxes over the Barents Sea and west of Spitsbergen are larger than those in autumn (up to $-140 \mathrm{~W} / \mathrm{m}^{2}$; Figure $4 \mathrm{a}$ ). The related local surface warming is up to $8 \mathrm{~K}$. Further, a statistically significant warming of up to $4 \mathrm{~K}$ appears over most parts of the Eastern Arctic Ocean (Figure 4a). The decreasing warming magnitude with increasing height results in weakened static stability in regions of sea ice loss (Figure 4b). Unlike in autumn, a significant and widespread remote temperature response is simulated, with a significant land surface cooling (of up to $-3 \mathrm{~K}$ ) over Alaska/North Canada and East Siberia. This cooling near the surface causes strengthened static stability there, which further decouples the surface from higher atmospheric layers and thus reinforces the surface cooling. The warming of the lower troposphere is confined to the Barents/Kara Seas region (Figure 4c) directly forced by the surface changes, while tropospheric cooling occurs over Alaska/North Canada, associated with the co-located surface cooling. Consistent with the regional warming/cooling patterns, positive/negative atmospheric moisture changes appear (Figure 4d).

[21] The lower atmospheric circulation changes show pronounced patterns (Figures $4 \mathrm{e}$ and $4 \mathrm{f}$ ). The atmospheric response shows a baroclinic structure in lower levels (below approximately $850 \mathrm{hPa}$ ), while it contains an equivalent barotropic contribution above approximately $850 \mathrm{hPa}$ over the Barents Sea and northwest Canada. A similar result of shallow baroclinic geopotential height response, which competes with equivalent barotropic structure aloft in midwinter, was found by Deser et al. [2010]. The pressure changes in the free atmosphere display significant wave-like 


\section{$\underline{\text { Region } 3 \text { (East Siberian/Chukchi Seas) }}$}
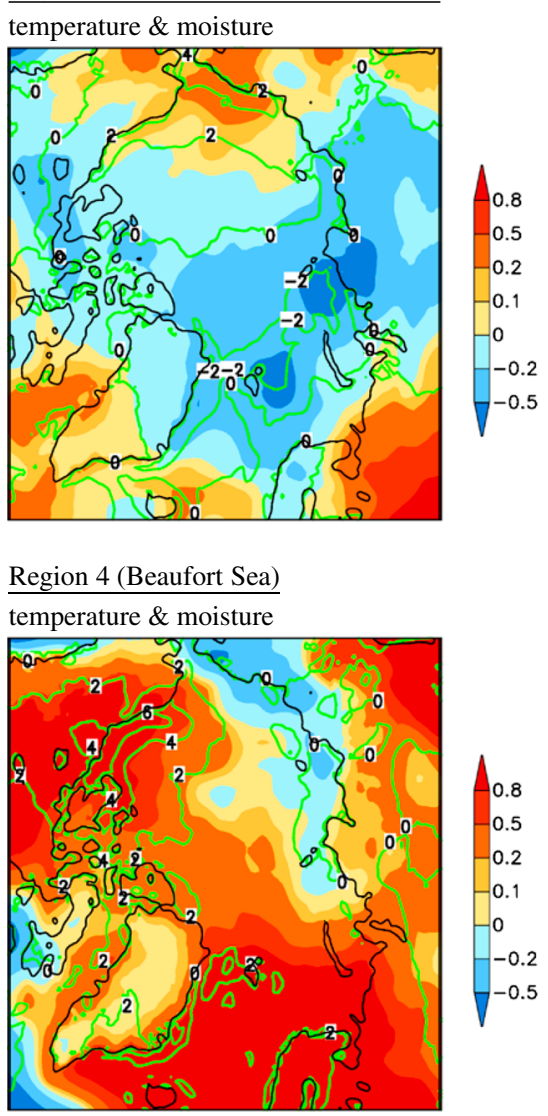

Figure 7.

anomalies across the Arctic, presenting a dipole pattern with increased geopotential heights over the Atlantic and Eastern Arctic and decreased geopotential heights over the central Arctic Ocean and Alaska/Northern Canada.

[22] The changes in SLP temporal standard deviation indicate changes in synoptic activity (Figure 4g). Compared with high-ice conditions, the North Atlantic storm track is modified in low-ice years. Its western branch which spreads over the Greenland Sea is strengthened, while the eastern branch which propagates toward the Barents/Kara Seas is weakened. The consequences of the latter are fewer cyclones over northern Siberia and a somewhat strengthened, northward expanded Siberian High, as also discussed by Inoue et al. [2012]. Like in autumn, compensating effects between the changes in synoptic activity and the baroclinic part of the long planetary waves are simulated (Figures $4 \mathrm{~g}$ and 4h), particularly over the North Atlantic and the Western Arctic. The simulated changes in the Eady growth rate (Figure 4h) point to strong regional variations in the growth of baroclinic disturbances. The simulations show an increase over the central Arctic, with a pronounced maximum in the Kara Sea region. This is associated with the above discussed decreased atmospheric stability there. Figure $4 \mathrm{~h}$ also shows a reduced Eady growth rate, and thus reduced baroclinicity farther south, particularly over Scandinavia, and the Beaufort Sea/adjacent land. This may indicate a northward shift of cyclonic activity in low-ice years, as discussed by Jaiser et al. [2012] on the basis of reanalysis data. A similar spatial pattern of Eady growth rate change
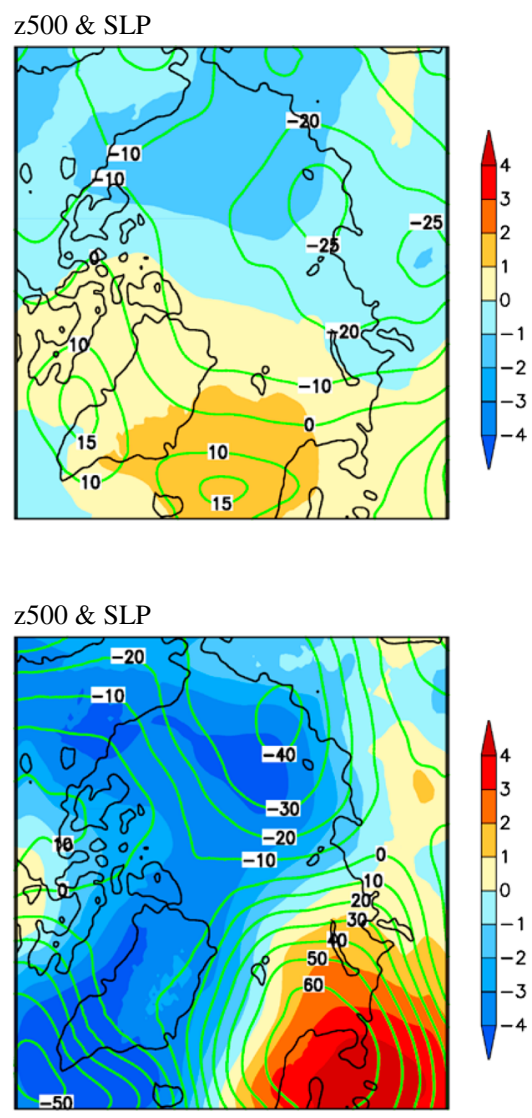

(continued)

is already established in the preceding autumn, but with much weaker magnitude (only half of that of winter; Figures $3 h$ and $4 h$ ).

\subsection{Uncertainty}

[23] The simulated feedbacks are robust in the sense that they appear consistently in each individual member of the ensemble. The degree of this consistency was calculated by means of the across-ensemble standard deviation (SD) and the related signal-to-noise ratio (SNR; see section 2.3.2) of the difference "low minus high sea ice." This kind of uncertainty (or robustness) quantification of the composite differences is presented in Figures 5 and 6 for autumn and winter, respectively.

[24] In both autumn and winter, the direct regional thermal feedback (warming) to sea ice loss and related increased heat fluxes is robust; i.e., the temperature increase is characterized by a small $\mathrm{SD}(\mathrm{SD}<1.5 \mathrm{~K})$ and a large SNR $(\mathrm{SNR}>3)$. SNR of temperature is, in many regions, even larger than 6 . The discussed land surface cooling over Alaska/North Canada and East Siberia during winter is also consistent and robust in the model (SNR $>1)$. In spite of the larger cooling magnitude, the robustness is a bit weaker in Alaska/North Canada $(\mathrm{SNR}=1-3)$ than in Siberia $(\mathrm{SNR}=1-6)$, which points to a larger internal variability in the Western Arctic. The associated moistening of the atmosphere (over the Eastern Arctic during autumn and over the Barents/Kara Seas during winter) is robust among the ensemble members $(\mathrm{SNR}>2)$. 
Region 1 (Barents/Kara Seas)
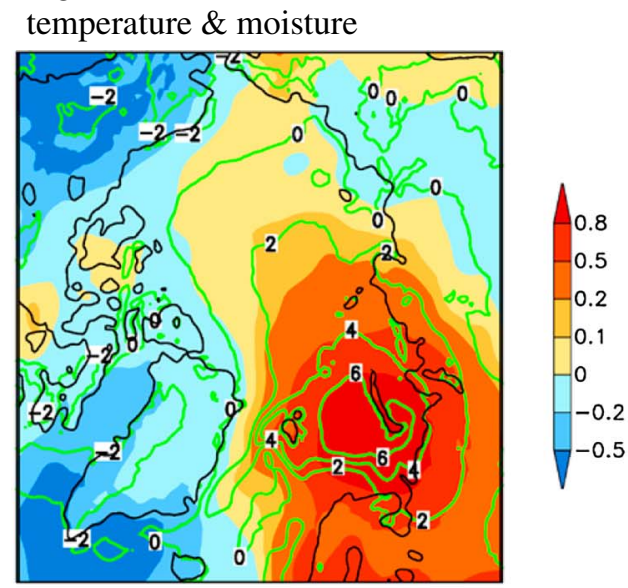

Region 2 (Laptev Sea)

temperature \& moisture

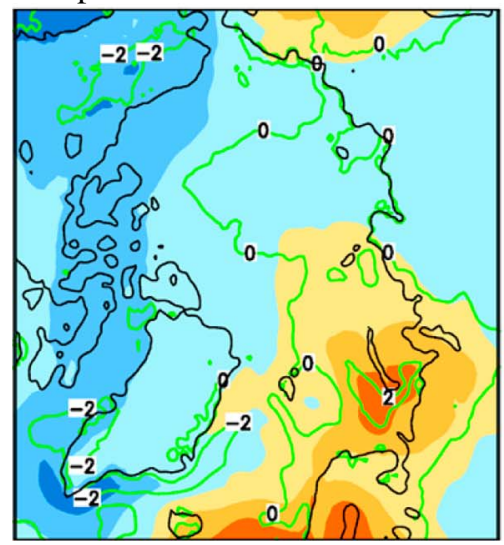

z500 \& SLP

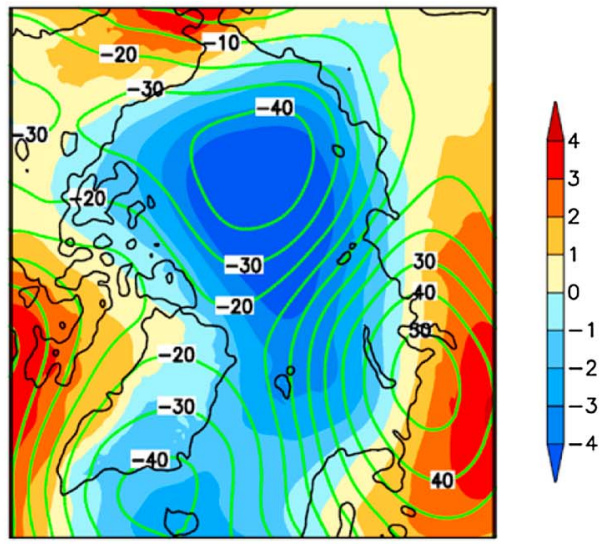

z500 \& SLP

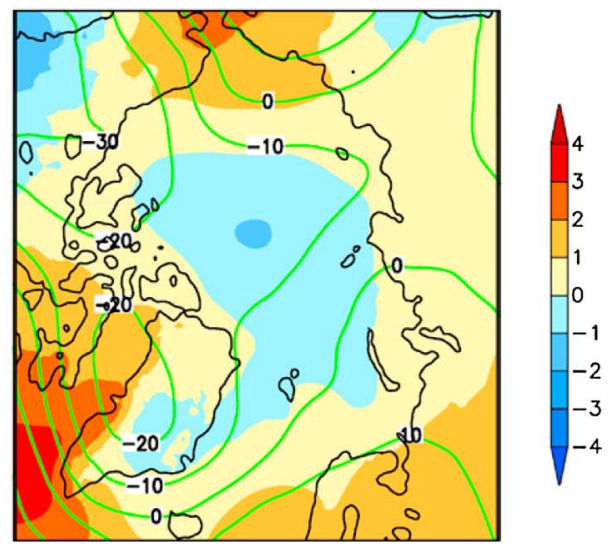

Figure 8. As in Figure 7 but for winter (DJF).

[25] The simulated atmospheric circulation changes contain a significant uncertainty (SNR $<2$ in most areas over the Arctic Ocean) in both autumn and winter. SD is of similar or even larger magnitude as the ensemble mean change (i.e., SNR $\leq 1$ ) in many regions of the Arctic Ocean. This result indicates that internally generated climate variability plays a prominent role, particularly during autumn, which was also discussed by Dorn et al. [2012] for summer and early autumn. In contrast, the simulated winter atmospheric circulation changes are larger and more consistent among the ensemble members. Here SNR of SLP and z500 changes is larger than 1 in many regions, which indicates that both the discussed SLP pattern and the wave-like z500 pattern across the Arctic are robust in the ensemble.

[26] Although our results concerning the mean response "low minus high ice" are based on a limited composite member size (69 low-ice cases and 39 high-ice cases), the sampling is high compared to the 15 -member ensemble from the only available (atmosphere-only) RCM study [Porter et al., 2012] and it is comparable to the 30-member ensemble study with the coupled European Centre for Medium-Range Weather Forecasts forecast model [Orsolini et al., 2012]. Only studies with coarser-resolution atmospheric general circulation models (AGCMs) allow for larger ensemble sizes [e.g., Liu et al., 2012; Kay et al., 2011]. Similar conclusions about the thermodynamic and dynamic responses in all these studies indicate that the underlying processes are well captured by the model. Further, we confirm that the presented model responses here are robust in terms of the ensemble size; that is, similar results were calculated even by using a smaller, three-member, ensemble (no figures shown here).

[27] Sea ice anomalies are generally associated with SST changes; i.e., also SST differences between low- and high-ice years contribute to the atmospheric response. However, most of the SST differences reflect the sea ice changes, including the associated heat flux changes. The SST changes over the northern North Atlantic are small (mostly less than $\pm 1 \mathrm{~K}$ ), so we argue that the considered sea ice anomaly is the most relevant factor for the atmospheric response, even though there might be compounding influences of sea ice and SST anomalies as well.

\section{Atmospheric Feedbacks to Regional September Arctic Sea Ice Anomalies}

[28] Bhatt et al. [2008] investigated an AGCM's sensitivity of the atmospheric response in summer to separately imposed 
Region 3 (East Siberian/Chukchi Seas)

temperature \& moisture

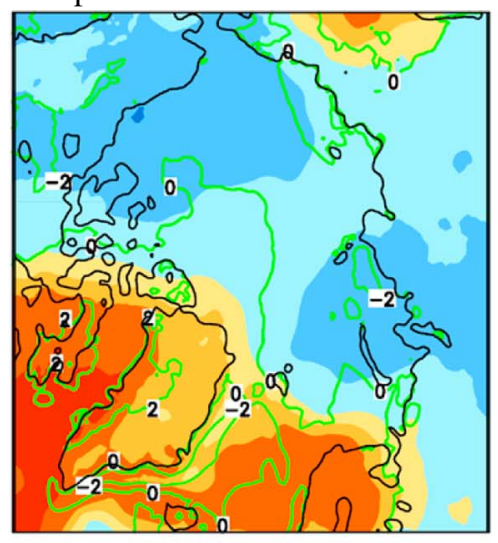

$\underline{\text { Region } 4 \text { (Beaufort Sea) }}$
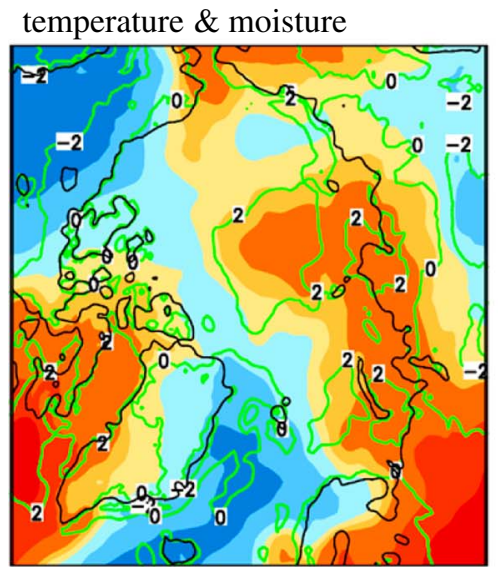

z500 \& SLP

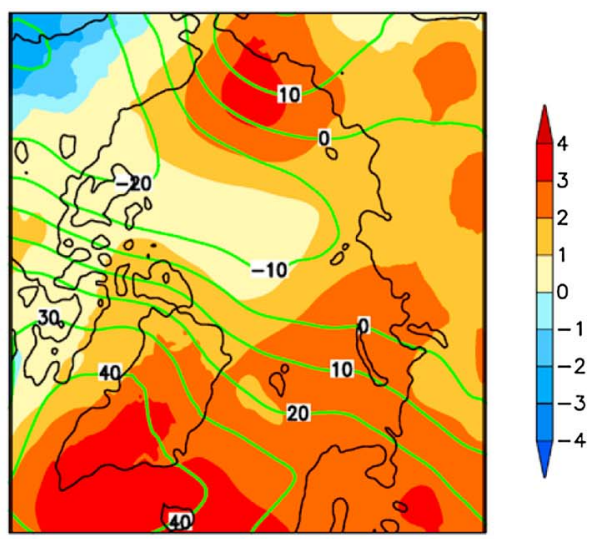

z500 \& SLP

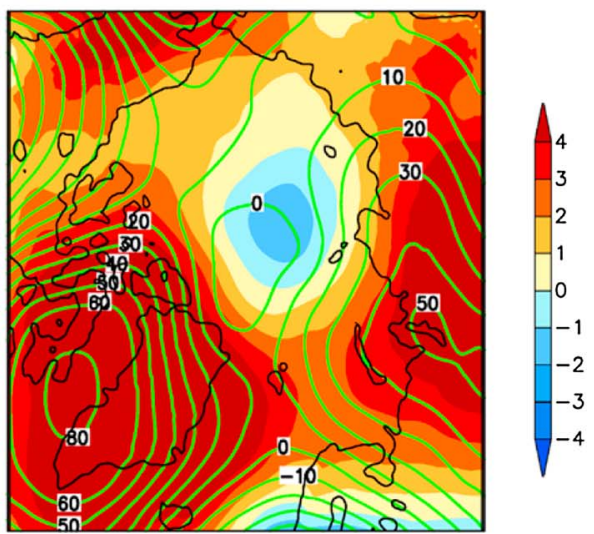

Figure 8. (continued)

summer sea ice anomalies in the Kara, Laptev/East Siberian, or Beaufort Sea and found that the atmospheric changes are similar to but weaker than the response to the full sea ice anomaly. Similarly, we asked: Are unique autumn and winter atmospheric patterns associated with specific regional sea ice anomalies in the preceding September in our coupled simulations? To discuss this, we follow the approach presented in section 2.2, using composites of September low- and highsea-ice years for four different sectors of the Arctic Ocean. The selected regions are indicated by white boxes in Figure 2. Region 1 covers the Barents and Kara Seas $\left(65-85^{\circ} \mathrm{N}\right.$, $\left.30-90^{\circ} \mathrm{E}\right)$, region 2 covers the Laptev Sea $\left(65-80^{\circ} \mathrm{N}\right.$, $\left.90-140^{\circ} \mathrm{E}\right)$, region 3 covers the total of the East Siberian Sea $\left(65-80^{\circ} \mathrm{N}, 140-180^{\circ} \mathrm{E}\right)$ and Chukchi Sea $\left(65-80^{\circ} \mathrm{N}\right.$, $\left.160-180^{\circ} \mathrm{W}\right)$, and region 4 covers the Beaufort Sea $\left(65-80^{\circ} \mathrm{N}\right.$, $\left.120-160^{\circ} \mathrm{W}\right)$. Because the strength of the regional sea ice area anomalies is quite different, the threshold to define low- and high-sea-ice years was accordingly adapted; a threshold of $70 \%$ was used for regions 1 and 2 (i.e., low- and high-ice cases were selected when the ice area anomaly was larger than $-70 \%$ and $+70 \%$, of mean values, respectively), while $30 \%$ was applied for regions 3 and 4. This ensures reasonable numbers of low- and high-sea-ice anomaly cases (at least 3, but mostly about 10) for each of the six ensemble members and each region.

\subsection{Autumn}

[29] In the following discussion, the atmospheric differences between these regional low- and high-ice composites are presented for autumn (see Figure 7). A sea ice anomaly in region 1 (Barents/Kara Seas) is connected with a quite similar atmospheric signal, both in the pattern and in the magnitude, as for the Arctic total sea ice area anomaly (see section 3.1.1; Figure 3). This is understandable because in terms of area and magnitude, the largest simulated Arctic sea ice anomalies in September occur over the Barents/Kara Seas (see Figure 2). The feedbacks produce an east-west dipole in moisture and temperature and a strong baroclinic circulation change, while a decreased SLP is simulated over most of the Arctic.

[30] Anomalously low sea ice in region 2 (Laptev Sea) is associated with regional near-surface temperature anomalies of up to $6 \mathrm{~K}$. A similar magnitude was found in idealized simulations by Ebner et al. [2011]. An associated cyclonic circulation anomaly over the Laptev/Kara Seas enhances warm air advection to East Siberia and cold air advection on its western flank. Also, the Icelandic Low is weakened. Related cooling and drying are simulated over Spitsbergen and the northern North Atlantic.

[31] In years with low sea ice in region 3 (East Siberian/ Chukchi Seas), regional temperature anomalies of up to $4 \mathrm{~K}$ appear. A distinct feature is the cooling/drying over the area 

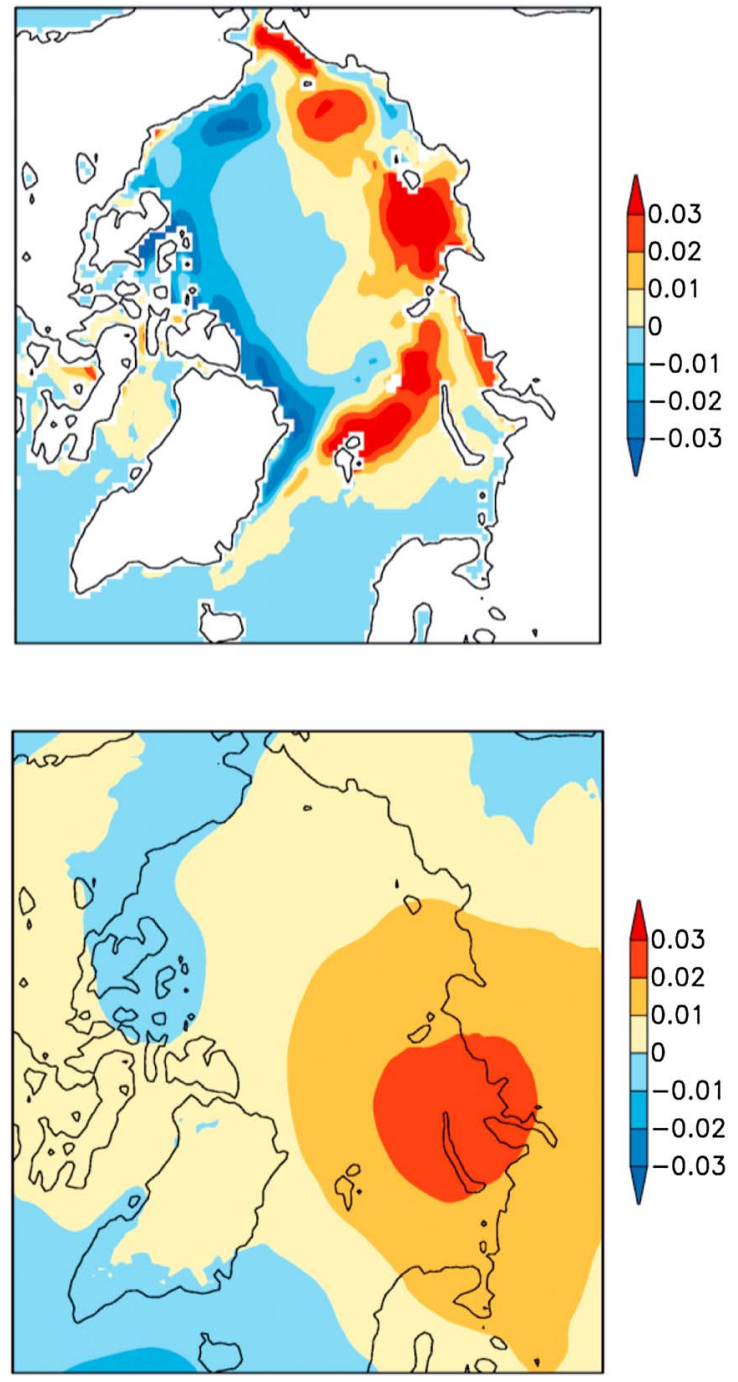

Figure 9. First pair of coupled patterns obtained by the maximum covariance analysis (MCA) of (top) simulated sea ice concentration (SIC) in September with (bottom) simulated sea level pressure (SLP) in autumn (SON), based on the HIRHAM-NAOSIM ensemble mean, for 1979-2008. The first patterns explain $36 \%$ of the covariance.

extending from Spitsbergen toward the Kara Sea, which is related to a SLP dipole with negative pressure anomalies over most of the Arctic (particularly over the East Siberian, Chukchi, and Laptev Seas) and positive pressure anomalies over the northern North Atlantic (i.e., less pronounced Icelandic Low).

[32] Loss of sea ice in region 4 (Beaufort Sea) results in a regional significant near-surface temperature increase of up to $6 \mathrm{~K}$. A similar impact of increased open water in the Beaufort Sea was discussed by Long and Perrie [2012] who applied a coupled atmosphere-ice-ocean model to simulating a summer storm in 2008. Consistent with Long and Perrie, our simulated circulation changes indicate the presence of baroclinic processes in the atmospheric response over the Western Arctic. Wendler et al. [2010] calculated correlation coefficients between the annual SIC in the Southern Beaufort Sea and different atmospheric indices, based on the period 1972-2007. Among others, they found a significant correlation for the Scandinavia Pattern index, sometimes also referred to as Eurasia-1 pattern. Our atmospheric response also corresponds to its positive phase, which is associated with positive height anomalies, sometimes reflecting major blocking anticyclones, over Scandinavia and Western Russia. Finally, compared to the other regions, the dynamic atmospheric feedbacks are strongest with respect to region-4 (Beaufort Sea) sea ice anomalies.

[33] The simulated east-west dipole in moisture and temperature signals (warming/moistening in the Eastern Arctic and cooling/drying in the Western Arctic), as seen in consequence of total Arctic sea ice area anomalies (section 3.1.1; Figure 3), is mainly caused by the feedback to low sea ice in the Barents/Kara and Laptev Seas. Feedbacks to the Beaufort Sea sea ice anomaly partly contribute to a warming/moistening of Alaska/Northern Canada, while the reduced warming/ moistening in the region expanding from Spitsbergen to the Kara Sea is due to the dynamic response to sea ice anomalies in the East Siberian/Chukchi Seas (compare Figures 3 and 7).

[34] In coupled models, we might expect complex relationships between sea ice conditions in different regions, which hamper the attribution of the atmospheric response to a one-region forcing. For instance, the simulations show an anticorrelation between Barents Sea (region 1) and East Siberian/Chukchi Seas (region 3) sea ice anomalies. This might be associated with a changed strength of the Beaufort Gyre and associated sea ice drift changes.

\subsection{Following Winter}

[35] Figure 8 shows the simulated winter atmospheric feedbacks to regional September sea ice loss. The winter is mainly dominated by the sea ice variability in the Barents/Kara Seas (Figure 2). The sea ice loss in that region can be larger than $-40 \%$ and thus larger than that in autumn. This, the larger temperature differences between atmosphere and ocean, and the larger planetary and baroclinic wave activities explain the generally larger magnitudes of the atmospheric changes related to the sea ice anomalies, compared with autumn.

[36] The simulated atmospheric feedback patterns for both region 1 (Barents/Kara Seas) and region 2 (Laptev Sea) are very similar: warming over the Barents/Kara Seas and cooling over the Western Arctic with centers over Alaska and the northern Labrador Sea; reduced pressure over the Arctic Ocean; and increased pressure over Northeast Canada/Baffin Bay, the Bering Strait region, and the Western Russian Arctic. However, the magnitude of the regional thermodynamic feedback to region-1 sea ice anomalies is much larger (increases in temperature of $6 \mathrm{~K}$ and in moisture of $0.8 \mathrm{~kg} / \mathrm{m}^{2}$ ). Also, the magnitudes of atmospheric circulation changes due to region-1 sea ice anomalies are more than twice larger than those due to region- 2 anomalies. The region- 1 feedbacks on SLP are up to $4 \mathrm{hPa}$ and on z500 up to $\pm 60 \mathrm{~m}$.

[37] The feedback patterns to region-4 (Beaufort Sea) anomalies also share most of the features discussed above. The main differences in the circulation feedback are expressed in the anomalously high pressure over the Baffin Bay region (up to $80 \mathrm{~m}$ in z500) and the more extensive positive pressure anomaly over the Western Russian Arctic. Associated with this, the reduced pressure over the central Arctic Ocean is limited to the northernmost region. Like in autumn, the atmospheric circulation feedbacks are strongest to region-4 sea ice anomalies. 
a)

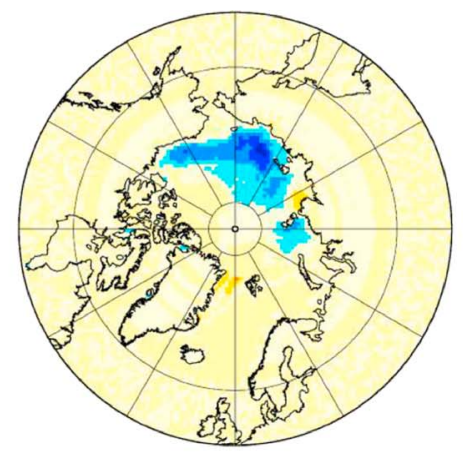

$-0.15-0.12-0.09-0.06-0.030 .000 .03 \quad 0.06 \quad 0.090 .120 .15$

b)

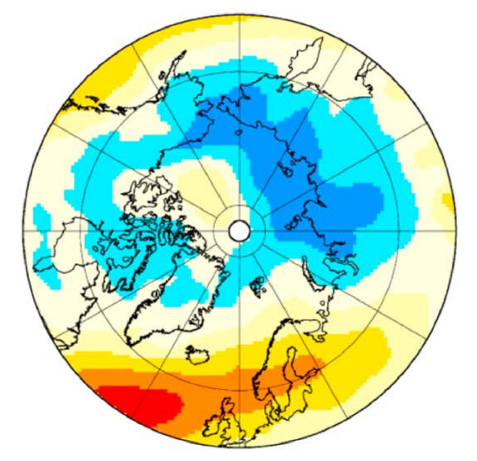

$-0.10-0.08-0.06-0.04-0.02 \quad 0.00 \quad 0.02 \quad 0.04 \quad 0.06 \quad 0.08 \quad 0.10$ c)

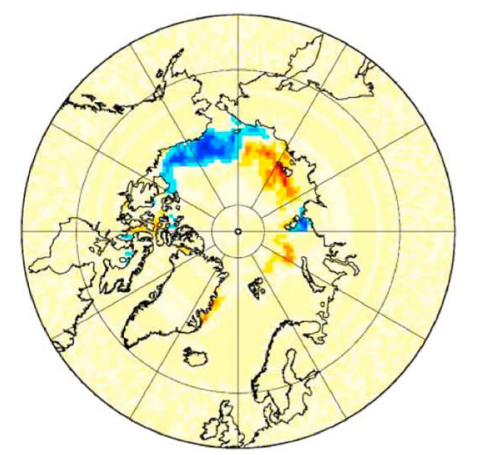

$-0.15-0.12-0.09-0.06-0.030 .000 .03 \quad 0.060 .090 .120 .15$

d)

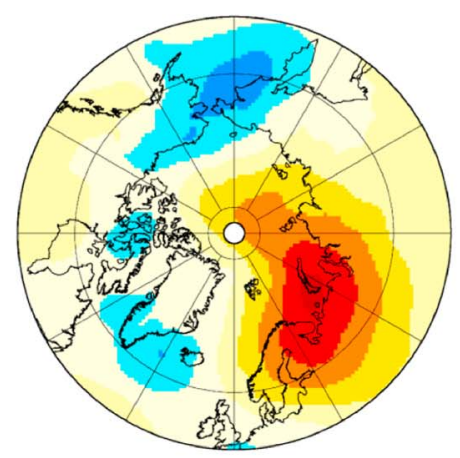

$-0.10-0.08-0.06-0.04-0.020 .000 .02 \quad 0.04 \quad 0.06 \quad 0.08 \quad 0.10$

Figure 10. (a, b) First pair and (c, d) second pair of coupled patterns obtained by the maximum covariance analysis (MCA) of HadISST1 sea ice concentration (SIC) in September in Figures 10a and 10c with ERAInterim sea level pressure (SLP) in autumn (SON) in Figures 10b and 10d, for 1979-2008. The first patterns explain $39 \%$ and the second patterns explain $19 \%$ of the covariance.

[38] The atmospheric feedback patterns to region-3 (East Siberian/Chukchi Seas) sea ice loss are completely different. Cooling and drying occur across the Arctic, with centers over the Beaufort and Kara Seas regions. This is associated with a significantly weakened Icelandic Low, a weakened North Atlantic storm track, and an anticyclonic anomaly along the Siberian coast connected with an extended Siberian High.

[39] In sum, regionally different September sea ice anomalies result in significantly different atmospheric circulation responses in the following winter, although in all cases, a winter sea ice anomaly occurs in the same region, the Barents Sea. This indicates that there is, on top of the response to the actual winter sea ice, a significant and specific lagged atmospheric circulation response to the specific late summer sea ice anomalies.

[40] The simulated cooling/drying over Alaska/North Canada, as seen in consequence of total Arctic sea ice area anomalies (section 3.1.2; Figure 4), is connected with feedbacks to low-ice conditions in the Barents/Kara Seas and Beaufort Sea, and with minor contribution from the Laptev Sea. The warming/moistening over the Barents/Kara Seas region is a clear thermodynamic response to the regional sea ice loss, which dynamically feeds back on reduced pressure over the Arctic Ocean and triggers the formation of the wave-like pattern across the Arctic.

\section{Further Statistical Evaluation of Sea Ice-Atmosphere Relations}

[41] To further understand the linkage between anomalies in Arctic sea ice in September and atmospheric circulation anomalies in both following autumn and winter, coupled patterns of SIC in September and SLP in autumn and winter were calculated by means of a maximum covariance analysis (MCA). The MCA was carried out for the fields of the whole period 1949-2008 as well as for the fields of the last 30 years 1979-2008 to enable a fair comparison with observational data. The results are only shown for the latter period, for autumn (Figures 9 and 10) and winter (Figures 11 and 12).

\subsection{Autumn}

[42] The analysis of the simulations for all 60 years 1949-2008 shows that the first MCA patterns (not shown) mostly resemble the calculated "low minus high ice" patterns (section 3.1.1; Figure 3). Sea ice reduction in the Barents, Kara, North Greenland, and Beaufort Seas is associated with SLP reduction over most parts of the Arctic Ocean and SLP increase over Scandinavia/North Europe and the West Russian Arctic. The MCA results also support the earlier finding that decreasing sea ice in 

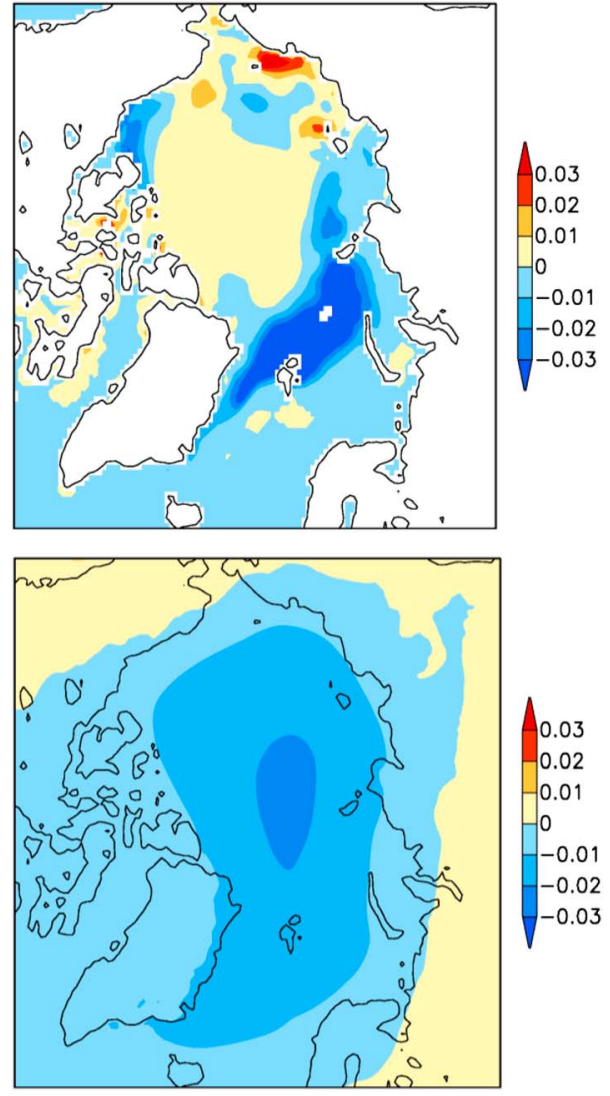

Figure 11. First pair of coupled patterns obtained by the maximum covariance analysis (MCA) of (top) simulated sea ice concentration (SIC) in September with (bottom) simulated sea level pressure (SLP) in winter (DJF), based on the HIRHAM-NAOSIM ensemble mean, for 1979-2008. The first patterns explain $50 \%$ of the covariance.

the Laptev Sea is accompanied by decreasing SLP over that region and increasing SLP over the Western Arctic, in agreement with the regional analysis (section 4.1; Figure 7).

[43] The simulated first MCA patterns for 1979-2008 (Figure 9) display that a sea ice dipole (reduction in the Eastern Arctic and increase in the Western Arctic) is associated with decreased SLP over the Barents/Kara Seas region and slight increase over the Labrador Sea/northern North Atlantic. This supports our findings with respect to feedbacks to regional sea ice anomalies in the Russian Seas (section 4.1; Figure 7). The simulated coupled first MCA patterns resemble the second MCA patterns from ERA-Interim/HadISST (Figures 10c and 10d).

[44] The first MCA patterns from ERA-Interim/HadISST (Figures 10a and 10b) show that sea ice reduction in the East Siberian/Chukchi Seas covaries with a SLP dipole with opposite pressure anomalies over most of the Arctic (particularly over the East Siberian, Chukchi, and Laptev Seas) (reduced pressure) and the northern North Atlantic (increased pressure). This coupled pair is difficult to find in the corresponding MCA of the simulations. However, this SLP dipole conforms with the simulated SLP feedback to region-3 (East Siberian/Chukchi Seas) sea ice anomalies (section 4.1; Figure 7). Thus, the atmospheric circulation feedbacks to such sea ice anomalies are represented in the model. It might be that such events of region-3 sea ice anomalies are underrepresented (in frequency and/or magnitude) in the simulations, compared with HadISST, such that analogous coupled SIC/SLP patterns with comparable strength are difficult to find in the MCA of the simulations. The realistic simulation of sea ice in the East Siberian/ Chukchi Seas region is a common problem of coupled climate models [see, e.g., Gerdes and Köberle, 2007; Holland et al., 2010; Kwok, 2011].

\subsection{Following Winter}

[45] The first MCA patterns for the period 1979-2008 of the simulations (Figure 11) show that reduced sea ice in the Barents/Kara Seas is associated with SLP decrease over the central Arctic and SLP increase over the Western Russian Arctic and Bering Strait region. This supports the finding about the atmospheric feedbacks to corresponding regional sea ice anomalies (section 4.2; Figure 8). Further, this is in accordance with the simulated differences "low minus high ice" (section 3.1.2; Figure 4).

[46] It is difficult to find exactly the same MCA patterns in both the simulations and the ERA-Interim/HadISST data (Figure 12). However, both the data and the model collectively show that sea ice reduction in the Eastern Arctic covaries with SLP reduction over the central Arctic. Concretely, the second MCA patterns of ERA-Interim/ HadISST display a wave-like SLP pattern with reduced pressure over the Arctic Ocean and increased pressure over subpolar regions (with centers over the Bering Strait region and Scandinavia/Western Russian Arctic), covarying with a dipole in sea ice variability (increase in the Beaufort/ Chukchi Seas and decrease in the Eastern Arctic Seas). This SLP pattern is, in principle, also found in the MCA of the simulations (Figure 11), but the related sea ice pattern is different, and therefore, the covarying SLP pattern also differs to some extent. Moreover, the simulated SLP feedback pattern "low minus high ice" (section 3.1.2; Figure 4) resembles the SLP variance of the second MCA pattern of the observational data.

\section{Summary and Conclusions}

[47] Atmospheric circulation changes connected with anomalous September sea ice are simulated in the coupled Arctic RCM HIRHAM-NAOSIM and lend support to and advance on earlier findings by identifying the pronounced sensitivity of the atmospheric response in autumn and winter to the location of the preceding September sea ice anomaly. The loss of sea ice increases the heat and moisture transfer from the ocean to the atmosphere with corresponding regional warming and moistening and decreasing atmospheric stability. The simulations show that the warming effect is felt throughout the atmospheric column, although it is strongest near the surface and in the ABL. The responses are due to coupled feedbacks between atmosphere, sea ice, and ocean, and not just an atmospheric response to sea ice anomalies. Thus, the dynamical interactions associated with changes in circulation also contribute to the temperature signals. We showed that the baroclinicity is modified, in particular, during the following winter. This is an indication that cyclogenesis and storm tracks can be affected by the sea ice anomalies, 
a)

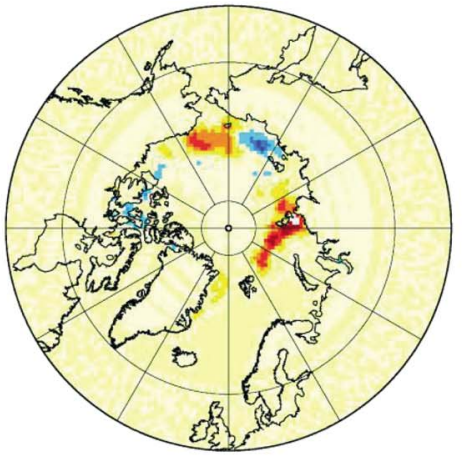

$-0.15-0.12-0.09-0.06-0.030 .000 .03 \quad 0.06 \quad 0.090 .120 .15$ c)

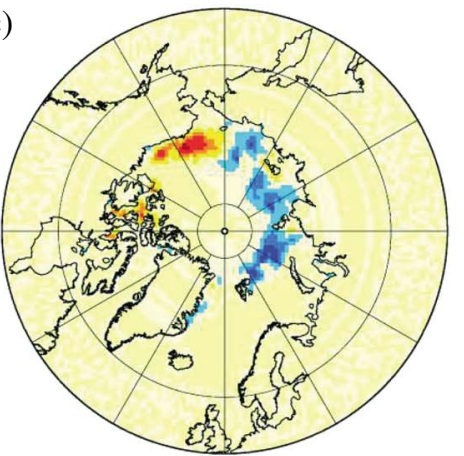

$-0.15-0.12-0.09-0.06-0.030 .000 .030 .060 .090 .120 .15$ b)

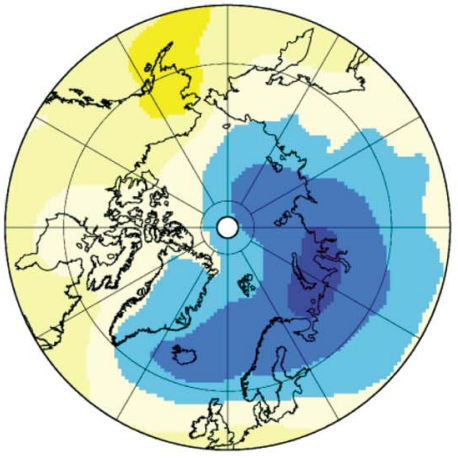

$-0.10-0.08-0.06-0.04-0.020 .000 .020 .040 .060 .080 .10$ d)

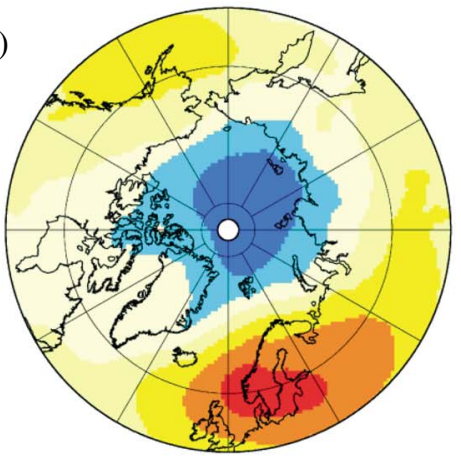

$-0.10-0.08-0.06-0.04-0.020 .000 .020 .04 \quad 0.06 \quad 0.08 \quad 0.10$

Figure 12. (a, b) First pair and $(c, d)$ second pair of coupled patterns obtained by the maximum covariance analysis (MCA) of HadISST1 sea ice concentration (SIC) in September in Figures 12a and 12c with ERAInterim sea level pressure (SLP) in winter (DJF) in Figures 12b and 12d, for 1979-2008. The first patterns explain $46 \%$ and the second patterns explain $16 \%$ of the covariance.

which have already been discussed on the basis of observational data, e.g., by Simmonds and Keay [2009] and Jaiser et al. [2012]. Our results indicate that changes in synoptic activity are partly compensated by opposite changes in planetary waves. This supports the finding by Sokolova et al. [2007], who suggested feedbacks between the time mean flow, the quasi-stationary planetary, and the baroclinic waves in response to sea ice changes. The simulated circulation changes indicate the presence of baroclinic processes in the atmospheric feedbacks, in accordance with observational analysis [Overland and Wang, 2010; Jaiser et al., 2012].

[48] The feedback chain, discussed in the literature and presented as motivation in section 1 , was simulated with the coupled model: September sea ice loss, increased heat
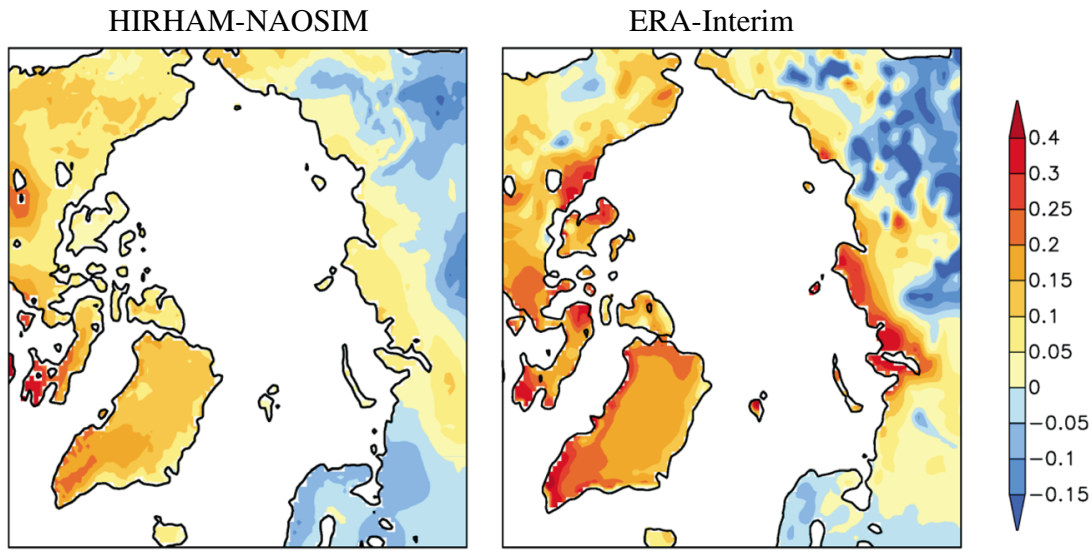

Figure 13. Spatial patterns of the linear trend of winter (DJF) land surface temperature $\left({ }^{\circ} \mathrm{C} / \mathrm{yr}\right)$, for 1988-2008, from the HIRHAM-NAOSIM ensemble mean and ERA-Interim data. 
and moisture fluxes, decreased vertical static stability and increased autumn lower tropospheric moisture, modified baroclinicity in winter, changes in wintertime large-scale circulation (e.g., an extended and strengthened Siberian High), and cold winter temperatures in northern Eurasia. However, cold winter temperatures in Northern Europe do not appear in the simulations, although the model successfully simulates the regional pattern of winter temperature trend in the last decades (Figure 13). In accordance with observations, the strongest cooling trends of up to $-1.5 \mathrm{~K} /$ decade are simulated over northern Eurasia [Cohen et al., 2012, Figure 1c]. This gives us some confidence that the model could be successfully used for seasonal predictability studies in the future.

[49] The often discussed negative Arctic Oscillation (AO) winter signal in response to summer sea ice loss (e.g., recently, Liu et al. [2012] and Jaiser et al. [2012]) is not found in the simulations. The simulated changes in winter atmospheric circulation are rather a wave-like pattern with decreasing pressure over the Arctic Ocean and increasing pressure over the Bering Strait and Baffin Bay regions, and Scandinavia/Western Russian Arctic. Our regional analysis suggests that this circulation feedback is linked to September sea ice anomalies in the regions of the Barents/ Kara, Laptev, and Beaufort Seas. This common SLP pattern is also found in the second MCA coupled pair from the ERA-Interim/HadISST data analysis for 1979-2008. However, the associated sea ice pattern is different in the model and the data. The SLP anomaly map of the first pair in the observational data shows some resemblance to the negative AO. Based on NCEP2 analysis for 1979-2010, Liu et al. [2012] noticed that the atmospheric winter response pattern to summer sea ice reduction shows not only some resemblance to the negative $\mathrm{AO}$ but also some significant differences, associated with a more meridional meandering, also discussed by Overland and Wang [2010]. Our results show that it remains difficult to release generally accepted conclusive statements or predictions. This is because the simulated atmospheric circulation feedbacks contain a significant uncertainty due to internally generated variability. Unlike temperature, the dynamical quantities like SLP and z500 show high internal variability in the model.

[50] Further, the atmospheric feedback patterns depend strongly on where the sea ice anomalies are located and which response time is considered. The Barents/Kara Seas and the Beaufort Sea are the most sensitive regions where sea ice anomalies feed back to the atmosphere much stronger than those in other regions. Sea ice anomalies in the Barents/Kara Seas show strong circulation feedbacks in winter but much weaker feedbacks in autumn, although the thermal response is of similar magnitude and has similar spatial patterns in both seasons. The strongest atmospheric feedbacks are simulated in relation to sea ice anomalies in the Beaufort Sea. However, compounding influences of sea ice and SST anomalies from different regions cannot be ruled out.

[51] As shown in the MCA, some of the simulated coupled SIC/SLP patterns are somewhat different from the HadISST/ ERA-Interim data. Thus, a future effort will be to further improve the sea ice simulation in the coupled model. Still, our results emphasize the other important fact that the simulated feedbacks depend on the time period considered; the simulated MCA patterns for 1949-2008 and 1979-2008 differ to some extent due to decadal-scale variability. Thus, conclusions from observational analyses which examined only the most recent time period should be considered with some caution as recently discussed by Hopsch et al. [2012].

[52] Acknowledgments. This research was supported by China's National Key Science Program for Global Change Research (2010CB950504, 2010CB951401, and 2012CB957704) and NSFC 41076125 and by the German Helmholtz Climate Initiative "Regional Climate Change" (REKLIM). We thank I. Hebestadt and S. Erxleben for the programming support. We thank the reviewers for their constructive comments, which have contributed to improve the manuscript.

\section{References}

Bhatt, U. S., M. A. Alexander, C. Deser, J. E. Walsh, J. S. Miller, M. S. Timli, J. Scott, and R. A. Tomas (2008), The atmospheric response to realistic reduced summer Arctic sea ice anomalies, in Arctic Sea Ice Decline: Observations, Projections, Mechanisms, and Implications, edited by E. T. DeWeaver, C. M. Bitz, and L.-B. Tremblay), American Geophysical Union, Washington, D.C, 91-110, doi:10.1029/180GM08.

Blüthgen, J., R. Gerdes, and M. Werner (2012), Atmospheric response to the extreme Arctic sea ice conditions in 2007, Geophys. Res. Lett., 39, L02707, doi:10.1029/2011GL050486.

Cohen, J. L., J. C. Furtado, M. A. Barlow, V. A. Alexeev, and J. E. Cherry (2012), Arctic warming, increasing snow cover and widespread boreal winter cooling, Environ. Res. Lett., 7, doi:10.1088/1748-9326/7/1/014007.

Dee, D. P., et al. (2011), The ERA-Interim reanalysis: Configuration and performance of the data assimilation system, Q.J.R. Meteorol. Soc., 137, 553-597, doi:10.1002/qj.828.

Deser, C., R. Tomas, M. Alexander, and D. Lawrence (2010), The seasonal atmospheric response to projected Arctic sea ice loss in the late 21st century, J. Clim., 23, 333-351, doi:10.1175/2009JCLI3053.1.

Dethloff, K., A. Rinke, R. Lehmann, J. H. Christensen, M. Botzet, and B. Machenhauer (1996), Regional climate model of the Arctic atmosphere, J. Geophys. Res., 101, 23,401-23,422.

Dorn, W., K. Dethloff, A. Rinke, S. Frickenhaus, R. Gerdes, M. Karcher, and F. Kauker (2007), Sensitivities and uncertainties in a coupled regional atmosphere-ocean-ice model with respect to the simulation of Arctic sea ice, J. Geophys. Res., 112, D10118, doi:10.1029/2006JD007814.

Dorn, W., K. Dethloff, and A. Rinke (2009), Improved simulation of feedbacks between atmosphere and sea ice over the Arctic Ocean in a coupled regional climate model, Ocean Model., 29, 103-114, doi:10.1016/j.ocemod.2009.03.010.

Dorn, W., K. Dethloff, and A. Rinke (2012), Limitations of a coupled regional climate model in the reproduction of the observed Arctic sea-ice retreat, The Cryosphere, 6, 985-998, doi:10.5194/tc-6-985-2012.

Ebner, L., D. Schröder, and G. Heinemann (2011), Impact of Laptev Sea flaw polynyas on the atmospheric boundary layer and ice production using idealized mesoscale simulations, Polar Res., 30, 7210, doi:10.3402/polar. v30i0.7210.

Francis, J. A., W. Chan, D. Leathers, J. R. Miller, and D. E. Veron (2009), Winter Northern Hemisphere weather patterns remember summer Arctic sea ice extent, Geophys. Res. Lett., 36, L07503, doi:10.1029/ 2009GL037274.

Gerdes, R., and C. Köberle (2007), Comparison of Arctic sea ice thickness variability in IPCC Climate of the 20th century experiments and in ocean-sea ice hindcasts, J. Geophys. Res., 112, C04S13, doi:10.1029/ 2006JC003616.

Ghatak, D., C. Deser, A. Frei, G. Gong, A. Phillips, D. A. Robinson, and J. Stroeve (2012), Simulated Siberian snow cover response to observed Arctic sea ice loss, 1979-2008, J. Geophys. Res., 117, D23108, doi:10.1029/2012JD018047.

Holland, M. M., M. C. Serreze, and J. Stroeve (2010), The sea ice mass budget of the Arctic and its future change as simulated by coupled climate models, Clim. Dyn., 34, 185-200, doi:10.1007/ s00382-008-0493-4.

Honda, M., J. Inoue, and S. Yamane (2009), Influence of low Arctic sea-ice minima on anomalously cold Eurasian winters, Geophys. Res. Lett., 36, L08707, doi:10.1029/2008GL037079.

Hopsch, S., J. Cohen, and K. Dethloff (2012), Analysis of a link between fall Arctic sea ice concentration and atmospheric patterns in the following winter, Tellus, 64, 18,624, doi:10.3402/tellusa.v64i0.18624.

Hoskins, B. J., and P. J. Valdes (1990), On the existence of storm-tracks, J. Atmos. Sci., 47, 1854-1864.

Inoue, J., M. E. Hori, and K. Takaya (2012), The role of Barents sea ice in the wintertime cyclone track and emergence of a warm-Arctic cold-Siberian anomaly, J. Clim., 25, 2561-2568, doi:10.1175/JCLI-D-11-00449.1. 


\section{RINKE ET AL.: ATMOSPHERIC FEEDBACKS TO ARCTIC SEA ICE}

Jaiser, R., K. Dethloff, D. Handorf, A. Rinke, and J. Cohen (2012), Impact of sea ice cover changes on the Northern Hemisphere atmospheric winter circulation, Tellus, 64, 11,595, doi:10.3402/tellusa.v64i0.11595.

Kalnay, E., et al. (1996), The NCEP/NCAR 40-year reanalysis project, Bull. Am. Meteorol. Soc., 77, 437-471.

Karcher, M. J., R. Gerdes, F. Kauker, and C. Köberle (2003), Arctic warming: Evolution and spreading of the 1990s warm event in the Nordic seas and the Arctic Ocean, J. Geophys. Res., 108(C2), 3034 doi:10.1029/2001JC001265.

Kauker, F., R. Gerdes, M. Karcher, C. Köberle, and J. L. Lieser (2003), Variability of Arctic and North Atlantic sea ice: A combined analysis of model results and observations from 1978 to 2001, J. Geophys. Res., 108(C6), 3182, doi:10.1029/2002JC001573.

Kay, J. E., and A. Gettelman (2009), Cloud influence on and response to seasonal Arctic sea ice loss, J. Geophys. Res., 114, 1-18, doi:10.1029/ 2009JD011773.

Kay, J. E., K. Raeder, A. Gettelman, and J. Anderson (2011), The boundary layer response to recent Arctic sea ice loss and implications for highlatitude climate feedbacks, J. Clim., 24, 428-447, doi:10.1175/ 2010JCLI3651.1.

Kwok, R. (2011), Observational assessment of Arctic Ocean sea ice motion, export, and thickness in CMIP3 climate simulations, J. Geophys. Res., 116, C00D05, doi:10.1029/2011JC007004.

Liu, J., J. A. Curry, H. Wang, M. Song, and R. M. Horton (2012), Impact of declining Arctic sea ice on winter snowfall, Proc. Natl. Acad. Sci., 109, 4074-4079, doi:10.1073/pnas.1114910109.

Long, Z., and W. Perrie (2012), Air-sea interactions during an Arctic storm, J. Geophys. Res., 117, D15103, doi:10.1029/2011JD016985.

Orsolini Y. J., R. Senan, R. E. Benestad, and A. Melsom (2012), Autumn atmospheric response to the 2007 low Arctic sea ice extent in coupled ocean-atmosphere hindcasts, Clim. Dyn., 38, D19108, 2437-2448, doi:10.1007/s00382-011-1169-z.

Overland, J. E., and M. Wang (2010), Large-scale atmospheric circulation changes are associated with the recent loss of Arctic sea ice, Tellus, 62, 1-9, doi:10.1111/j.1600-0870.2009.00421.x.

Petoukhov, V., and V. A. Semenov (2010), A link between reduced BarentsKara sea ice and cold winter extremes over northern continents, J. Geophys. Res., 115, D21111, doi:10.1029/2009JD013568.

Porter, D. F., J. J. Cassano, and M. C. Serreze (2012), Local and large-scale atmospheric responses to reduced Arctic sea ice and ocean warming in the WRF model, J. Geophys. Res., 117, D11115, doi:10.1029/2011JD016969.

Rayner, N. A., D. E. Parker, E. B. Horton, C. K. Folland, L. V. Alexander, D. P. Rowell, E. C. Kent, A. Kaplanet (2003), Global analyses of sea surface temperature, sea ice, and night marine air temperature since the late nineteenth century, J. Geophys. Res., 108(D14), 4407, doi:10.1029/ 2002JD002670.

Rinke, A., R. Gerdes, K. Dethloff, T. Kandlbinder, M. Karcher, F. Kauker, S. Frickenhaus, C. Köberle, and W. Hiller (2003), A case study of the anomalous Arctic sea ice conditions during 1990: Insights from coupled and uncoupled regional climate model simulations, J. Geophys. Res., 108(D9), 4275, doi:10.1029/2002JD003146.

Schweiger, A. J., R. Lindsay, S. Vavrus, and J. Francis (2008), Relationships between Arctic sea ice and clouds during autumn, J. Clim., 21, 4799-4810.

Screen, J. A., I. Simmonds, C. Deser, and R. Tomas (2013), The atmospheric response to three decades of observed Arctic sea ice loss, J. Clim., 26 , 1230-1248, doi:10.1175/JCLI-D-12-00063.1.

Simmonds, I., and K. Keay (2009), Extraordinary September Arctic sea ice reductions and their relationships with storm behavior over 1979-2000, Geophys. Res. Lett., 36, L19715, doi:10.1029/2009GL039810.

Sokolova, E., K. Dethloff, A. Rinke, and A. Benkel (2007), Planetary and synoptic scale adjustment of the Arctic atmosphere to sea ice cover changes, Geophys. Res. Lett., 34, L17816, doi:10.1029/2007GL030218.

Strey, S. T., W. L. Chapman, and J. E. Walsh (2010), The 2007 sea ice minimum: Impacts on the Northern Hemisphere atmosphere in late autumn and early winter, J. Geophys. Res., 115, D23103, doi:10.1029/ 2009JD013294.

Tang, Q., X. Zhang, X. Yang, and J. A. Francis (2013), Cold winter extremes in northern continents linked to Arctic sea ice loss, Environ. Res. Lett., 8 , 014036, doi:10.1088/1748-9326/8/1/014036.

Teng, H., W. M. Washington, and G. A. Meehl (2008), Interannual variations and future change of wintertime extratropical cyclone activity over North America in CCSM3, Clim. Dyn., 30, 673-686, doi:10.1007/ s00382-007-0314-1.

von Storch, H., and F. W. Zwiers (1999), Statistical Analysis in Climate Research, 494 pp., Cambridge University Press, Cambridge, UK.

Wendler, G., M. Shulski, and B. Moore (2010), Changes in the climate of the Alaskan North Slope and the ice concentration of the adjacent Beaufort Sea, Theor. Appl. Climatol., 99, 67-74, doi:10.1007/s00704-009-0127-8.

Wu, B., J. Wang, and J. E. Walsh (2006), Dipole anomaly in the winter Arctic atmosphere and its association with sea ice motion, J. Clim., 19, 210-225.

Zhang, X., A. Sorteberg, J. Zhang, R. Gerdes, and J. C. Comiso (2008), Recent radical shifts of atmospheric circulations and rapid changes in Arctic climate system, Geophys. Res. Lett., 35, L22701, doi:10.1029/ 2008 GL035607. 